\title{
Identification and statistical optimization of fermentation conditions for a newly isolated extracellular cholesterol oxidase- producing Streptomyces cavourensis strain NEAE-42
}

\author{
Noura El-Ahmady El-Naggar ${ }^{*}$, Nancy M. El-Shweihy and Sara M. El-Ewasy
}

\begin{abstract}
Background: Due to broad range of clinical and industrial applications of cholesterol oxidase, isolation and screening of bacterial strains producing extracellular form of cholesterol oxidase is of great importance.

Results: One hundred and thirty actinomycete isolates were screened for their cholesterol oxidase activity. Among them, a potential culture, strain NEAE-42 is displayed the highest extracellular cholesterol oxidase activity. It was selected and identified as Streptomyces cavourensis strain NEAE-42. The optimization of different process parameters for cholesterol oxidase production by Streptomyces cavourensis strain NEAE-42 using Plackett-Burman experimental design and response surface methodology was carried out. Fifteen variables were screened using Plackett-Burman experimental design. Cholesterol, initial $\mathrm{pH}$ and $\left(\mathrm{NH}_{4}\right)_{2} \mathrm{SO}_{4}$ were the most significant positive independent variables affecting cholesterol oxidase production. Central composite design was chosen to elucidate the optimal concentrations of the selected process variables on cholesterol oxidase production. It was found that, cholesterol oxidase production by Streptomyces cavourensis strain NEAE-42 after optimization process was $20.521 \mathrm{U} / \mathrm{mL}$ which is higher than result obtained from the basal medium before screening process using Plackett-Burman $(3.31 \mathrm{U} / \mathrm{mL})$ with a fold of increase 6.19.
\end{abstract}

Conclusions: The cholesterol oxidase level production obtained in this study $(20.521 \mathrm{U} / \mathrm{mL})$ by the statistical method is higher than many of the reported values.

Keywords: Cholesterol oxidase, Streptomyces cavourensis strain NEAE-42, Plackett-Burman design, Central composite design, Identification, 16S rRNA

\section{Background}

Cholesterol oxidase (3ß-hydroxysteroid oxidase, EC 1.1.3.6) is a flavin adenine dinucleotide (FAD)-dependent enzyme belongs to the family of oxidoreductases, specifically those acting on the $\mathrm{CH}-\mathrm{OH}$ group of donor with oxygen as acceptor that in most cases catalyzes the oxidation and isomerization of cholesterol (cholest-5-en-3 $\beta$-ol) using oxygen as an electron acceptor to form 4-cholesten-3one (cholestenone) and hydrogen peroxide [1].
Cholesterol oxidase enzyme is simple, specific, and furthermore profoundly sensitive; utilized for the clinical determination of cholesterol levels in serum, HDL, or LDL for the evaluation of atherosclerotic illnesses and different lipid problems and also for assessing the danger of thrombosis [2]. A high blood cholesterol level is regarded to be related to cardiovascular disorder and its degradation products (cholesterol oxides) have been hypothesized to be associated with colon cancer [3].

\footnotetext{
* Correspondence: nouraelahmady@yahoo.com

Department of Bioprocess Development, Genetic Engineering and

Biotechnology Research Institute, City of Scientific Research and

Technological Applications, New Borg El-Arab City, Alexandria 21934, Egypt
} 
Therefore, it has been proposed that bacterial degradation of cholesterol in cholesterol containing foods might also be beneficial for human health [4]. In addition, cholesterol oxidase has been used for the bioconversion of a variety of sterols and non-steroidal compounds, allylic alcohols [5]. Moreover, cholesterol oxidase has potential applications as a biocatalyst which can be used as an insecticide that is a necessary part of pest manages strategies using transgenic crops [6]. Cholesterol oxidase is additionally implicated in the manifestation of some of the bacterial diseases (tuberculosis), viral (HIV) and non-viral prion origin (Alzheimer's) [7]. In current years, a variety of electrochemical biosensors using the immobilized cholesterol oxidase have been pronounced for the determination of cholesterol in serum or food [8]. Since the assays using this enzyme are simple, specific, and distinctly sensitive compared with the traditional chemical methods, its use has emerged widespread. Cholesterol oxidases can additionally be used to produce a precursor for chemical synthesis of steroid hormones [1] and to degrade of dietary cholesterol in foods [4].

Cholesterol oxidase is an extracellular or an intracellular enzyme produced by many microorganisms. Cholesterol oxidases may additionally be intrinsic membrane bound enzymes located on the outside of the cell or can be recovered from broth filtrate as an extracellular enzyme. Cholesterol oxidases have been recovered from different microorganisms such as Nocardia [9], Streptomyces [10] and Streptoverticillium [11]. Cholesterolassimilating bacteria produce a cholesterol oxidase, which is involved in the first step of cholesterol metabolism [12]. Some pathogenic bacteria possess cholesterol oxidases, which are a major membrane-damaging factor and consequently implicated in the pathogenicity of these bacteria [13].

The objective of this study is to obtain an efficient cholesterol oxidase producer for industrial and medicinal needs, to optimize culture conditions using response surface methodology for high production of cholesterol oxidase by Streptomyces cavourensis strain NEAE-42.

\section{Methods}

\section{Microorganisms and cultural conditions}

Streptomyces spp. used in this study are local isolates isolated from various soil samples collected from different localities of Egypt and kindly provided by Dr. Noura El-Ahmady El-Naggar (Department of Bioprocess Development, Genetic Engineering and Biotechnology Research Institute, City of Scientific Research and Technological Applications, Alexandria, Egypt). These isolates were maintained on slopes containing starch-nitrate agar medium of the following composition (g/L): Starch 20; $\mathrm{KNO}_{3} 2 ; \mathrm{K}_{2} \mathrm{HPO}_{4} \quad$ 1; $\mathrm{MgSO}_{4} .7 \mathrm{H}_{2} \mathrm{O} 0.5 ; \mathrm{NaCl} 0.5 ; \mathrm{CaCO}_{3} 3 ; \mathrm{FeSO}_{4} .7 \mathrm{H}_{2} \mathrm{O} 0.01$; agar 20 and distilled water up to $1 \mathrm{~L}$. The isolates were stored as spore suspensions in $20 \%(\mathrm{v} / \mathrm{v})$ glycerol at $-20{ }^{\circ} \mathrm{C}$ for subsequent investigation.

\section{Qualitative screening for cholesterol oxidase producing microorganisms using colony staining method}

Cholesterol oxidase is the enzyme which able to convert cholesterol into hydrogen peroxide and cholest-4-en-3one. Medium consists of $(\mathrm{g} / \mathrm{L})$ : Cholesterol 2, $\mathrm{KNO}_{3} 2$, $\mathrm{K}_{2} \mathrm{HPO}_{4} 1, \mathrm{MgSO}_{4} .7 \mathrm{H}_{2} \mathrm{O} 0.5, \mathrm{NaCl} 0.5, \mathrm{CaCO}_{3} 3, \mathrm{FeS}-$ $\mathrm{O}_{4} .7 \mathrm{H}_{2} \mathrm{O} 0.01$, agar 20 and distilled water up to $1 \mathrm{~L}$ was used for plate screening. Agar plates were seeded with spores of actinomycetes and incubated at $30{ }^{\circ} \mathrm{C}$ for 7 days. Cholesterol oxidase producing potentialities was performed on the grown colonies using colony staining method. Discs of filter papers were dipped into the solution containing $0.5 \%$ cholesterol; $1.7 \%$ 4-aminoantipyrine; $6 \%$ phenol and 3000U/l horseradish peroxidase in $100 \mathrm{mM}$ potassium buffer phosphate (pH 7.0). Thereafter, soaked discs had been located on grown colonies on the plates and incubated at room temperature for $24 \mathrm{~h}$. Development of pink color in the medium surrounding the tested colonies due to the quinoneimine dye formation is due to the activity of cholesterol oxidase [14]. The strain which showed the most promising result was selected for further investigations.

\section{Inoculum preparation}

$250 \mathrm{~mL}$ Erlenmeyer flasks containing $100 \mathrm{~mL}$ of broth medium containing: glucose $12 \mathrm{~g} / \mathrm{L}$; starch $9 \mathrm{~g} / \mathrm{L}$; yeast extract $6 \mathrm{~g} / \mathrm{L}$; peptone $4 \mathrm{~g} / \mathrm{L}$; $\left(\mathrm{NH}_{4}\right)_{2} \mathrm{SO}_{4} 7.5 \mathrm{~g} / \mathrm{L}$; cholesterol $2 \mathrm{~g} / \mathrm{L} ; \mathrm{K}_{2} \mathrm{HPO}_{4} 1 \mathrm{~g} / \mathrm{L} ; \mathrm{MgSO}_{4} .7 \mathrm{H}_{2} \mathrm{O} 0.5 \mathrm{~g} / \mathrm{L}$; $\mathrm{FeSO}_{4} .7 \mathrm{H}_{2} \mathrm{O} 0.02 \mathrm{~g} / \mathrm{L} ; \mathrm{NaCl} 1 \mathrm{~g} / \mathrm{L} ; \mathrm{MnSO}_{4} 0.008 \mathrm{~g} / \mathrm{L}$; $\mathrm{CaSO}_{4} 0.002 \mathrm{~g} / \mathrm{L} ; \mathrm{ZnSO}_{4} 0.002 \mathrm{~g} / \mathrm{L} ; \mathrm{CaCl}_{2} 0.0002 \mathrm{~g} / \mathrm{L}$; Tween $800.05 \mathrm{~g} / \mathrm{L}$ [15] were inoculated with $9 \mathrm{~mm}$ diameter five disks taken from the 7 days old stock culture grown on starch nitrate agar medium. The inoculated flasks were incubated for $48 \mathrm{~h}$ in a rotatory shaker incubator at $30{ }^{\circ} \mathrm{C}$ and $200 \mathrm{rpm}$ and were used as inoculum for subsequent experiments.

\section{Production conditions}

$100 \mathrm{~mL}$ of fermentation medium were dispensed in $250 \mathrm{~mL}$ Erlenmeyer conical flasks, inoculated with the previously prepared inoculum. The inoculated flasks were incubated on a rotatory shaker incubator at 150 $200 \mathrm{rpm}$ and $30-37{ }^{\circ} \mathrm{C}$. After the specified incubation time for each set of experimental trials, the mycelium of the isolate was collected by centrifugation at $6000 \mathrm{rpm}$ for $15 \mathrm{~min}$. The cell free supernatant was used for assay of the enzyme activity. 


\section{Assay of enzyme activity}

Cholesterol oxidase activity was measured by hydrogen peroxide estimation generated during cholesterol oxidation process. In this reaction, hydrogen peroxide was coupled with 4-aminoantipyrine and phenol by peroxides to produce quinoneimine dye with maximum absorption at $500 \mathrm{~nm}$. Cholesterol dissolved in Triton X100 (non-ionic detergent) was used as substrate for the reaction. The reaction mixture was consisted of $3 \mu \mathrm{mol}$ of cholesterol in $1.0 \mathrm{~mL}$ of $1 \%$ Triton X-100, $300 \mu \mathrm{mol}$ of phosphate buffer, $\mathrm{pH}$ 7.0, $0.1 \mathrm{~mL}$ of enzyme solution, $21 \mu \mathrm{mol}$ of phenol and $20 \mathrm{U}$ of horseradish peroxidase, $1.2 \mu \mathrm{mol}$ of 4 -aminoantipyrine in a final volume of $3 \mathrm{~mL}$. Reaction was incubated at $37{ }^{\circ} \mathrm{C}$ for $10 \mathrm{~min}$ with shaking. This reaction was terminated by heating at $100{ }^{\circ} \mathrm{C}$ for $3 \mathrm{~min}$. One enzyme unit was defined as the amount of enzyme that librated $1 \mu \mathrm{mol}$ of $\mathrm{H}_{2} \mathrm{O}_{2}$ per minute at $37^{\circ} \mathrm{C}$.

\section{Morphology and cultural characteristics of the selected strain}

The spore chain morphology and the spore surface ornamentation of strain NEAE- 42 were examined on inorganic salt/starch agar (ISP medium 4) after incubation for 14 days at $30{ }^{\circ} \mathrm{C}$ using the coverslip technique of Kawato and Shinobu [16]. The dehydrated, gold-coated specimen can be examined with Analytical Scanning Electron Microscope Jeol JSM-6360 LA operating at 20 $\mathrm{Kv}$ at different magnifications at the Central Laboratory, City of Scientific Research and Technological Applications, Alexandria, Egypt. Cultural characteristics were observed on ISP media 1-7 according to the methods described by Shirling and Gottlieb [17]; all plates were incubated at $30^{\circ} \mathrm{C}$ for 14 days.

\section{Chemotaxonomy and physiological characteristics}

The whole-cell sugars were identified by high performance liquid chromatography analysis. Carbon source utilization was tested on plates containing ISP basal medium 9 and melanoid pigment production was examined following the methods of Shirling and Gottlieb [17] on ISP media 1, 6 and 7. Sodium chloride tolerance was determined according to the methods of Tresner et al. [18]. Casein degradation was evaluated following the method of Gordon et al. [19] and reduction of nitrates to nitrites was examined [20]. Liquefaction of gelatin was determined by using the method of Waksman [21]. The ability for coagulation or peptonization of milk was evaluated as described by Cowan and Steel [22]. According to the method of Nitsch and Kützner [23], Lecithinase activity was conducted on egg-yolk medium and the capacity to decompose cellulose was tested following the method of Ariffin et al. [24]. The strain ability to produce $\alpha$-amylase was determined [25]. The antimicrobial activity of the organism was tested against four bacterial (Staphylococcus aureus, Pseudomonas aeruginosa, Klebsiella and Escherichia coli), and five fungal strains (Alternaria solani, Rhizoctonia solani, Fusarium oxysporum, Bipolaris oryzae and Fusarium solani).

\section{S rRNA sequencing}

The preparation of genomic DNA of the strain was conducted in accordance with the methods described by Sambrook et al. [26]. The PCR amplification reaction was performed according to the methods described by El-Naggar et al. [27]. Sequencing was performed and sequencing product was deposited in the GenBank database under accession number KJ676478.

\section{Sequence alignment and phylogenetic analysis}

The 16S rRNA gene sequence of strain NEAE- 42 was aligned with the corresponding 16S rRNA sequences of the type strains of representative members of the genus Streptomyces retrieved from the GenBank, DDBJ, EMBL and PDB databases by using BLAST program (https://blast.ncbi.nlm.nih.gov/Blast.cgi?PAGE_TYPE=BlastSearch) [28]. Multiple alignment and phylogenetic tree analysis was performed using the software package MEGA4 version 2.1 [29], the tree was constructed using the neighbour-joining method of Saitou and Nei [30]. The phylogenetic tree, sequence data and alignments used to produce the results displayed in Fig. 3 have been deposited in TreeBASE (https://treebase.org/treebase-web/home.html).

\section{Screening of main factors influences cholesterol oxidase production by Plackett-Burman design}

In order to determine the variables affecting cholesterol oxidase production, different nutritional and environmental variables were evaluated in a two-steps experimental design strategy. In the first step, a two factorial design, Plackett-Burman statistical experimental design, is used to identify the critical variables which required for elevation of cholesterol oxidase production. Plackett-Burman statistical experimental design is very useful for screening the most important factors for enzyme production with respect to their main effects [31, 32]. The total number of the experiments which must be carried out according to Plackett-Burman design is $n+1$, where $n$ is the number of variables [33]. A total of 15 independent (assigned) and four unassigned variables (which commonly referred as dummy variables) were screened in Plackett-Burman experimental design. Dummy variables $\left(D_{1}-D_{4}\right)$ are used to estimate experimental errors in data analysis. The fifteen different independent variables are shown in Table 1 including cholesterol, starch, glucose, yeast extract, peptone, 
Table 1 Experimental independent variables at two levels used for the production of cholesterol oxidase by Streptomyces cavourensis strain NEAE-42 using Plackett-Burman design

\begin{tabular}{|c|c|c|c|}
\hline \multirow[t]{2}{*}{ Code } & \multirow[t]{2}{*}{ Variables } & \multicolumn{2}{|c|}{ Levels } \\
\hline & & -1 & +1 \\
\hline$A$ & Temperature $\left({ }^{\circ} \mathrm{C}\right)$ & 30 & 37 \\
\hline B & Incubation time (days) & 5 & 7 \\
\hline C & Inoculum size $(\%, v / v)$ & 2 & 4 \\
\hline $\mathrm{D}$ & Agitation speed (rpm) & 150 & 200 \\
\hline$E$ & $\mathrm{pH}$ & 7 & 8.5 \\
\hline $\mathrm{F}$ & Glucose (g/L) & 10 & 15 \\
\hline G & Starch $(g / L)$ & 7 & 10 \\
\hline $\mathrm{H}$ & Cholesterol (g/L) & 1 & 2 \\
\hline J & Yeast extract (g/L) & 4 & 6 \\
\hline K & Peptone (g/L) & 3 & 5 \\
\hline$L$ & Ammonium sulphate $(\mathrm{g} / \mathrm{L})$ & 6 & 8 \\
\hline M & $\mathrm{K}_{2} \mathrm{HPO}_{4}(\mathrm{~g} / \mathrm{L})$ & 0.5 & 1 \\
\hline N & $\mathrm{NaCl}(\mathrm{g} / \mathrm{L})$ & 0.5 & 1 \\
\hline $\mathrm{O}$ & $\mathrm{MgSO}_{4}(\mathrm{~g} / \mathrm{L})$ & 0.2 & 0.5 \\
\hline$P$ & $\mathrm{FeSO}_{4}(\mathrm{~g} / \mathrm{L})$ & 0.0 & 0.02 \\
\hline
\end{tabular}

$\left(\mathrm{NH}_{4}\right)_{2} \mathrm{SO}_{4}, \mathrm{~K}_{2} \mathrm{HPO}_{4}, \mathrm{NaCl}, \mathrm{MgSO}_{4}, \mathrm{FeSO}_{4}$, temperature, incubation time, inoculum size, agitation speed and $\mathrm{pH}$ were chosen to be screened by Plackett Burman experiment. Each variable is represented at two levels, high and low denoted by $(+)$ and $(-)$, respectively. The experiment in 20 runs was conducted to study the selected variables effect on cholesterol oxidase production. All trials were performed in duplicate and the average of cholesterol oxidase activities were used as responses. Plackett-Burman experimental design is based on the first order model:

$$
Y=\beta_{0}+\sum \beta_{i} X_{i}
$$

Where, $\mathrm{Y}$ is cholesterol oxidase activity (response or dependent variable), $\beta_{0}$ is the model intercept and $\beta_{i}$ is the linear coefficient, and $X_{\mathrm{i}}$ is the level of the independent variable.

\section{Optimization of cholesterol oxidase production by response surface methodology}

The central composite design (CCD) under the response surface methodology (RSM) was used to elucidate the optimal values of the most significant independent variables. In this study, the experimental plan consisted of 20 runs and the independent variables were studied at five different levels $(-1.68,-1,0,1,1.68)$. All the runs were performed in duplicate and the average of obtained cholesterol oxidase activity was taken as the dependent variable or response $(\mathrm{Y})$. The experimental results were fitted to the following second order polynomial model:

$$
Y=\beta_{0}+\sum_{i} \beta_{i} X_{i}+\sum_{i i} \beta_{i i} X_{i}^{2}+\sum_{i j} \beta_{i j} X_{i} X_{j}
$$

In which $Y$ is the predicted response, $\beta_{0}$ is the regression coefficients, $\beta_{\mathrm{i}}$ is the linear coefficient, $\beta_{\mathrm{ii}}$ is the quadratic coefficients, $\beta_{\mathrm{ij}}$ is the interaction coefficients, $X_{i}$ and $X_{j}$ are coded levels of independent variables.

\section{Statistical analysis}

Design Expert ${ }^{\circ} 7.0$ software version 7 (Stat-Ease Inc., USA) for Windows was used for the experimental designs and statistical analysis. The statistical software package, STATISTICA software (Version 8.0, StatSoft Inc., Tulsa, USA) was used to plot the three-dimensional surface plots, in order to illustrate the relationship between the responses and the experimental levels of each of the variables utilized in this study.

\section{Results and Discussion}

The total of one hundred and thirty morphologically different actinomycete strains were qualitative screened for their cholesterol oxidase activity using colony staining method, formation of pink zones around the colonies indicated the presence of cholesterol oxidase activity. The strain which showed the large pink zone around the colony was selected for further experiments. The selected strain was cultured in $100 \mathrm{~mL}$ of fermentation medium and the cell free supernatant was used for enzyme activity assay. The most promising isolate was selected and identified based on morphological, cultural, physiological and chemotaxonomic properties, as well as 16S rRNA sequence.

\section{Morphological and cultural characteristics}

Cultural properties of strain NEAE-42 are shown in Table 2. Aerial mass color is white to olive beige on yeast extract-malt extract agar (ISP medium 2) and olive green on starch-nitrate agar medium (Fig. 1a). Strain NEAE-42 grew well on ISP medium 2-7. The color of the substrate mycelium was not sensitive to $\mathrm{pH}$ changes. The mycelium does not fragment and the verticils are not present. Diffusible pigments were faint brown on most test media.

The scanning electron micrograph of strain NEAE-42 which cultured on starch nitrate agar medium revealed that the organism produced an extensively branched substrate mycelium and aerial hyphae which differentiated into Rectiflexibiles type spore-chains carrying more than 50 elongated, irregular and smooth-surfaced spores (Fig. 2). 
Table 2 Culture characteristics of the Streptomyces sp. strain NEAE-42

\begin{tabular}{llll}
\hline Medium & Color of & & \\
\cline { 2 - 3 } & Aerial mycelium & Substrate mycelium & Diffusible pigment \\
\hline $\begin{array}{l}\text { ISP medium 2 } \\
\text { (Yeast extract -malt extract agar) }\end{array}$ & White to olive beige & Brown & Faint brown \\
$\begin{array}{l}\text { IS medium 3 } \\
\text { ISP medium } 4 \\
\text { (Inorganic salt-starch agar) }\end{array}$ & Olive green & Olive brown & Faint brown \\
$\begin{array}{l}\text { ISP medium } 5 \\
\text { (Glycerol asparagines agar) }\end{array}$ & Olive green & Olive brown & Faint brown \\
$\begin{array}{l}\text { ISP medium 6 } \\
\text { (Peptone-yeast extract iron agar) }\end{array}$ & Olive beige & Brown & Faint brown \\
$\begin{array}{l}\text { ISP medium } 7 \\
\text { (Tyrosine agar) }\end{array}$ & Faint beige & Faint yellowish brown & Non-pigmented \\
\hline
\end{tabular}

The substrate mycelium pigment was not $\mathrm{pH}$ sensitive when tested with $0.05 \mathrm{~N} \mathrm{NaOH}$ or $0.05 \mathrm{~N} \mathrm{HCl}$

The diffusible pigment was $\mathrm{pH}$ sensitive when tested with $0.05 \mathrm{~N} \mathrm{NaOH}$ or $0.05 \mathrm{~N} \mathrm{HCl}$, yellow in acidic, brown in alkaline

\section{Chemotaxonomy and physiological characteristics}

The physiological and biochemical characteristics of strain NEAE-42 are shown in Table 3. The strain produced faint brown diffusible pigments on most test media. Production of melanin was positive on peptoneyeast extract iron agar medium. Starch hydrolysis, casein hydrolysis, milk coagulation and peptonization (Fig. 1b) and nitrate reduction were positive. Gelatin liquification and lecithin degradation were negative. $\alpha$-amylase (starch hydrolysis), cellulase (growth on cellulose), protease (degradation of casein), chitosanase, uricase and asparaginase of strain NEAE-42 were produced while lecithinase, and gelatinase were not produced. Strain NEAE- 42 has no antimicrobial activities against Staphylococcus aureus, Bacillus subtilis, Escherichia coli, Pseudomonas aeruginosa, Klebsiella pneumonia, Alternaria solani, Bipolaris oryzae, Rhizoctonia solani, Fusarium oxysporum, Aspergillus niger, and Candida albicans. D (-) fructose, D (+) galactose,
D (+) xylose, L-arabinose, D (+) glucose, ribose, sucrose, D $(+)$ mannose, cellulose and maltose are utilized for growth but trehalose is not utilized for growth. No growth or only traces of growth with rhamnose and raffinose. The wholecell hydrolysates contained mainly xylose and galactose.

On the basis of cultural, morphological and chemotaxonomic properties above, as well as the physiological properties of strain NEAE-42 shown in Table 3, it is evident that strain NEAE-42 belongs to the genus Streptomyces [34].

\section{$16 \mathrm{~S}$ rRNA gene sequence comparisons and phylogenetic analysis}

The strain NEAE-42 16S rRNA gene sequence was deposited in the GenBank database under the accession number KJ676478. The complete (1510 bp) sequence of strain NEAE-42 was aligned with the sequences of the genus Streptomyces members retrieved from the GenBank

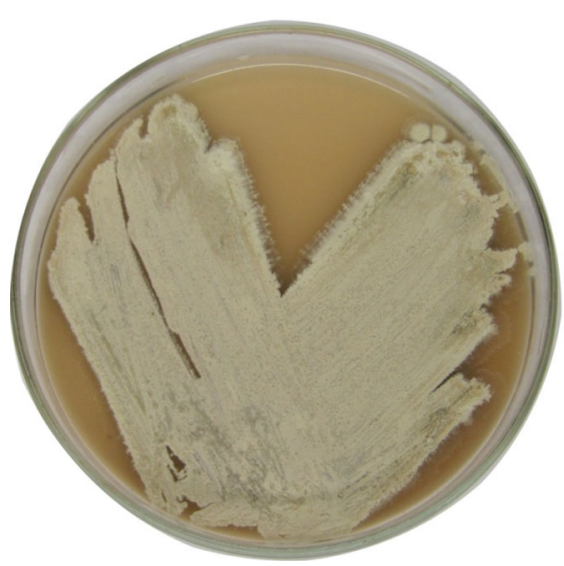

a

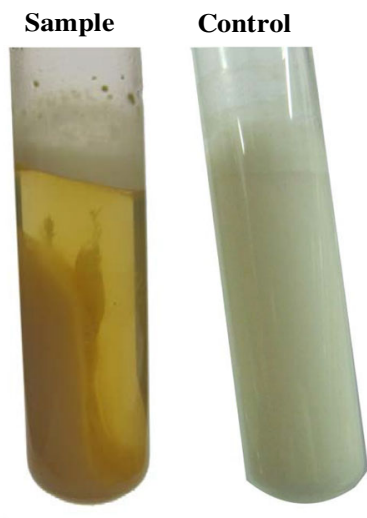

b

Fig. 1 a Color of the aerial mycelium of Streptomyces sp. NEAE-42 grown on starch-nitrate agar medium for $7-14$ days of incubation at $30{ }^{\circ} \mathrm{C}$, b coaggulation and peptonization of milk 

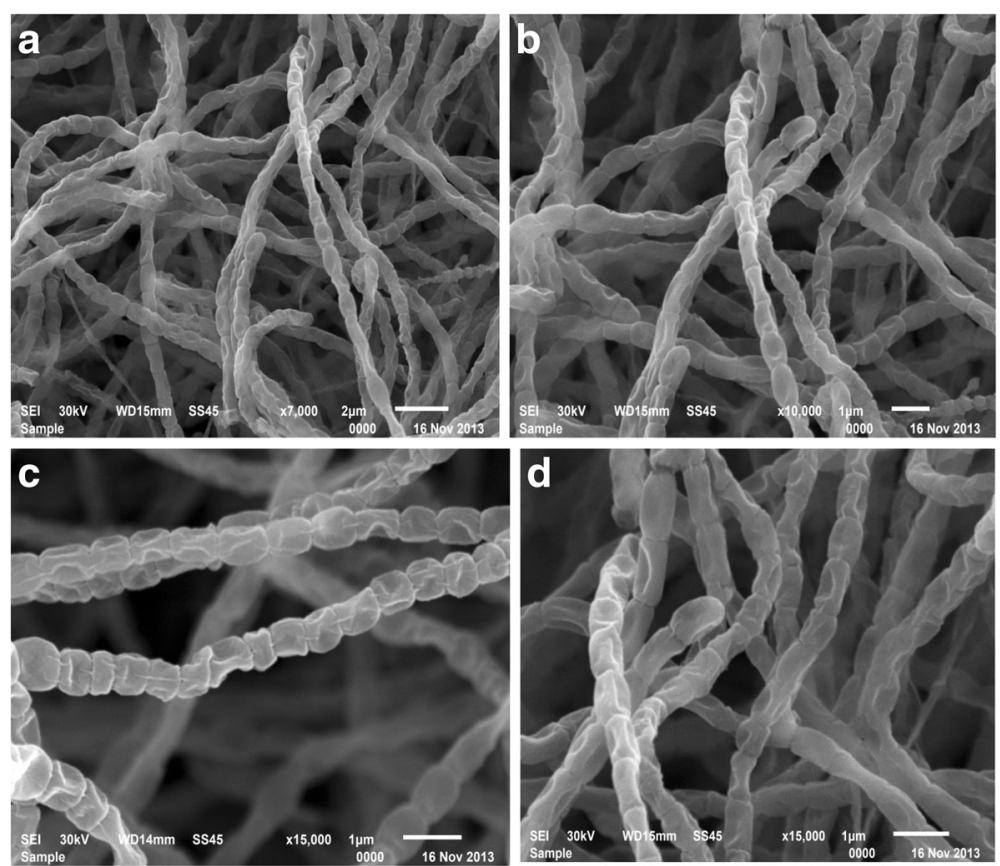

Fig. 2 Scanning electron micrograph showing the spore-chain morphology and spore-surface ornamentation of strain NEAE -42 grown on starch nitrate agar medium for 14 days at $30^{\circ} \mathrm{C}$ at magnification of $7000 \times(\mathbf{a}), 10000 \times(\mathbf{b})$ and $15000 \times(\mathbf{c}, \mathbf{d})$

databases by using BLAST [28]. The phylogenetic tree (Fig. 3) showed that the isolate falls into one distinct clade with Streptomyces flavolimosus strain CGMCC 2027 (GenBank accession no. EF688620.1), Streptomyces cavourensis subsp. washingtonensis NRRLB-8030 (GenBank accession no. DQ026671.1), Streptomyces badius strain CB00830 (GenBank accession no. HF935087.1), Streptomyces flavogriseus strain P.S.461 (GenBank accession no. KF991651.1), Streptomyces fimicarius strain IHB B 12014 (GenBank accession no. KF475818.1) and Streptomyces microflavus strain 173397(GenBank accession no. EU570660.1) with which it shared $16 \mathrm{~S}$ rRNA gene sequence maximum identity of $99.0 \%$.

Based on the collected data and the comparative study of the isolate No. NEAE-42 (Table 3) in relation to the recorded properties of closest related species of the genus Streptomyces, it is most closely related to the type strains of Streptomyces cavourensis subsp. washingtonensis NRRLB-8030 (GenBank accession no. DQ026671.1) (99 \% sequence similarity) [35]. Therefore, this strain was identified as Streptomyces cavourensis strain NEAE-42.

\section{Statistical screening of fermentation process variables affecting cholesterol oxidase production by Streptomyces cavourensis strain NEAE-42 using two-level fractional factorial design, Plackett-Burman design}

Plackett-Burman (PB) design was used to determine which variables significantly affect cholesterol oxidase production by Streptomyces cavourensis strain NEAE-42.
Compared with other medium design strategies, the Plackett-Burman design is simple, fast method suitable for screening multiple variables in one experiment and is often used to evaluate the most important and significant variables affecting culture requirements for fermentation and enzyme production. In order to evaluate the effect of physical parameters (temperature, incubation time, inoculum size, agitation speed, $\mathrm{pH}$ ), carbon sources (cholesterol, starch, glucose), nitrogen sources (yeast extract, peptone, $\left.\left(\mathrm{NH}_{4}\right)_{2} \mathrm{SO}_{4}\right)$, in addition to energy sources $\left(\mathrm{K}_{2} \mathrm{HPO}_{4}\right)$, and metals $\left(\mathrm{NaCl}, \mathrm{MgSO}_{4} \cdot 7 \mathrm{H}_{2} \mathrm{O}, \mathrm{FeSO}_{4}\right.$. $7 \mathrm{H}_{2} \mathrm{O}$ ) for the maximum production of cholesterol oxidase by Streptomyces cavourensis strain NEAE-42, Plackett-Burman design was applied to determine the most important factors.

The Plackett-Burman design for the nineteen variables along with the corresponding responses for cholesterol oxidase production are shown in Table 4. Plackett-Burman experiments showed wide variation $(0.000$ to $6.910 \mathrm{U} / \mathrm{mL})$ in cholesterol oxidase production; this variation reflected the importance of medium optimization to attain higher cholesterol oxidase production.

Statistical analysis by multiple-regression model of cholesterol oxidase activities was performed which is represented in Tables 5, 6. Table 5 and Fig. 4a shows the main effect of each variable on the cholesterol oxidase production. With respect to the main effect of each variable, we can see that ten variables from the fifteen different independent variables named cholesterol, starch, 
Table 3 Phenotypic properties that separate strain Streptomyces NEAE-42 from related Streptomyces species. Data for reference species were taken mainly from Bergey's Manual of Systematic Bacteriology -volume five the actinobacteria [35]

\begin{tabular}{|c|c|c|c|c|c|c|c|}
\hline Characteristic & $\begin{array}{l}\text { Streptomyces sp. strain } \\
\text { NEAE-42 }\end{array}$ & Streptomyces cavourensis & $\begin{array}{l}\text { Streptomyces } \\
\text { flavolimosus }\end{array}$ & Streptomyces badius & $\begin{array}{l}\text { Streptomyces } \\
\text { flavogriseus }\end{array}$ & $\begin{array}{l}\text { Streptomyces } \\
\text { fimicarius }\end{array}$ & $\begin{array}{l}\text { Streptomyces } \\
\text { microflavus }\end{array}$ \\
\hline $\begin{array}{l}\text { Aerial mass color on ISP } \\
\text { mdeium } 2\end{array}$ & White to olive beige & Yellow or white & $\begin{array}{l}\text { White or pale } \\
\text { yellow }\end{array}$ & $\begin{array}{l}\text { Yellow or intermediate } \\
\text { between gray and yellow }\end{array}$ & Gray & Yellow or white & $\begin{array}{l}\text { Gray or yellow } \\
\text { color }\end{array}$ \\
\hline $\begin{array}{l}\text { Reverse side of colony on } \\
\text { ISP medium } 2\end{array}$ & Brown & Moderate to strong brown & & No distinctive pigments & $\begin{array}{l}\text { Strong yellow or } \\
\text { orange-yellow }\end{array}$ & $\begin{array}{l}\text { Orange or reddish } \\
\text { brown }\end{array}$ & $\begin{array}{l}\text { No distinctive } \\
\text { pigments }\end{array}$ \\
\hline $\begin{array}{l}\text { Production of diffusible } \\
\text { pigment }\end{array}$ & Faint brown & Brown & Yellow to brown & Not formed & $\begin{array}{l}\text { No pigment, or only } \\
\text { a trace of yellow }\end{array}$ & Red & $\begin{array}{l}\text { No pigment } \\
\text { formed }\end{array}$ \\
\hline Spore chain morphology & Rectiflexibles & Rectiflexibiles & Rectiflexibiles & Rectiflexibiles & Rectiflexibiles & Rectiflexibiles & Rectiflexibiles \\
\hline Spore surface & $\begin{array}{l}\text { Smooth with surface } \\
\text { irregularities }\end{array}$ & $\begin{array}{l}\text { Smooth, sometimes with } \\
\text { minor surface irregularities }\end{array}$ & Smooth & Smooth & Smooth & Smooth & Smooth \\
\hline Spore shape & Rectangular & & Oval-shaped & & & & \\
\hline $\begin{array}{l}\text { Sensitivity of diffusible } \\
\text { pigment to } \mathrm{pH}\end{array}$ & $\begin{array}{l}\text { Yellow in acidic, brown } \\
\text { in alkaline }\end{array}$ & & & & & $\begin{array}{l}\text { changing to yellow } \\
\text { in acidic }\end{array}$ & \\
\hline \multicolumn{8}{|l|}{ Melanin production on } \\
\hline $\begin{array}{l}\text { Peptone-yeast extract iron } \\
\text { agar }\end{array}$ & + & + & - & - & - & - & - \\
\hline Tyrosine agar & - & - & - & \pm & - & - & - \\
\hline Tryptone-yeast extract broth & - & + & - & \pm & - & - & - \\
\hline $\begin{array}{l}\text { Maximum } \mathrm{NaCl} \text { tolerance }(\%, \\
\mathrm{w} / \mathrm{v})\end{array}$ & 7 & 7.5 & & 5 & & & 2.5 \\
\hline \multicolumn{8}{|l|}{ Degradation of } \\
\hline Lecithin & - & & & & & & \\
\hline Casein & + & & & & & & \\
\hline Starch & + & & + & & & & \\
\hline Coagulation of milk & + & & - & & & & \\
\hline Peptonization of milk & + & & - & & & & \\
\hline Nitrate reduction & + & & + & & & & \\
\hline Gelatin liquification & - & & - & & & & \\
\hline \multicolumn{8}{|c|}{ Utilization of carbon sources $(1 \%, \mathrm{w} / \mathrm{v})$} \\
\hline$D(-)$ fructose & + & + & + & + & + & + & + \\
\hline$D(+)$ xylose & + & + & - & + & + & + & + \\
\hline $\mathrm{D}(+)$ galactose & + & & - & & & & \\
\hline
\end{tabular}


Table 3 Phenotypic properties that separate strain Streptomyces NEAE-42 from related Streptomyces species. Data for reference species were taken mainly from Bergey's Manual of Systematic Bacteriology -volume five the actinobacteria [35] (Continued)

\begin{tabular}{|c|c|c|c|c|c|c|c|}
\hline $\mathrm{D}(+)$ glucose & + & + & + & + & + & + & + \\
\hline L-arabinose & + & + & + & + & + & + & \pm \\
\hline Ribose & + & & & & & & \\
\hline $\mathrm{D}(+)$ mannose & + & + & & - & + & + & + \\
\hline Sucrose & + & \pm & - & \pm & - & \pm & \pm \\
\hline Maltose & + & & & & & & \\
\hline Rhamnose & \pm & \pm & - & \pm & + & + & + \\
\hline Raffinose & \pm & \pm & & \pm & - & \pm & \pm \\
\hline Cellulose & + & & - & - & + & + & \\
\hline Trehalose & - & & & & & & \\
\hline
\end{tabular}

The optimal growth temperature was $30^{\circ} \mathrm{C}$ and optimal pH was 7.0. Strain NEAE-42 has no antimicrobial activities against Staphylococcus aureus, Bacillus subtilis, Escherichia coli, Pseudomonas aeruginosa, Klebsiella pneumonia, Alternaria solani, Bipolaris oryzae, Rhizoctonia solani, Fusarium oxysporum, Aspergillus niger, and Candida albicans. a-amylase (starch hydrolysis), protease (degradation of casein), cellulase (growth on cellulose), uricase, chitosanase and asparaginase of strain NEAE-42 were produced while lecithinase, and gelatinase were not produced Abbreviations: + Positive, - Negative, \pm Doubtful, Blank cells no data available 


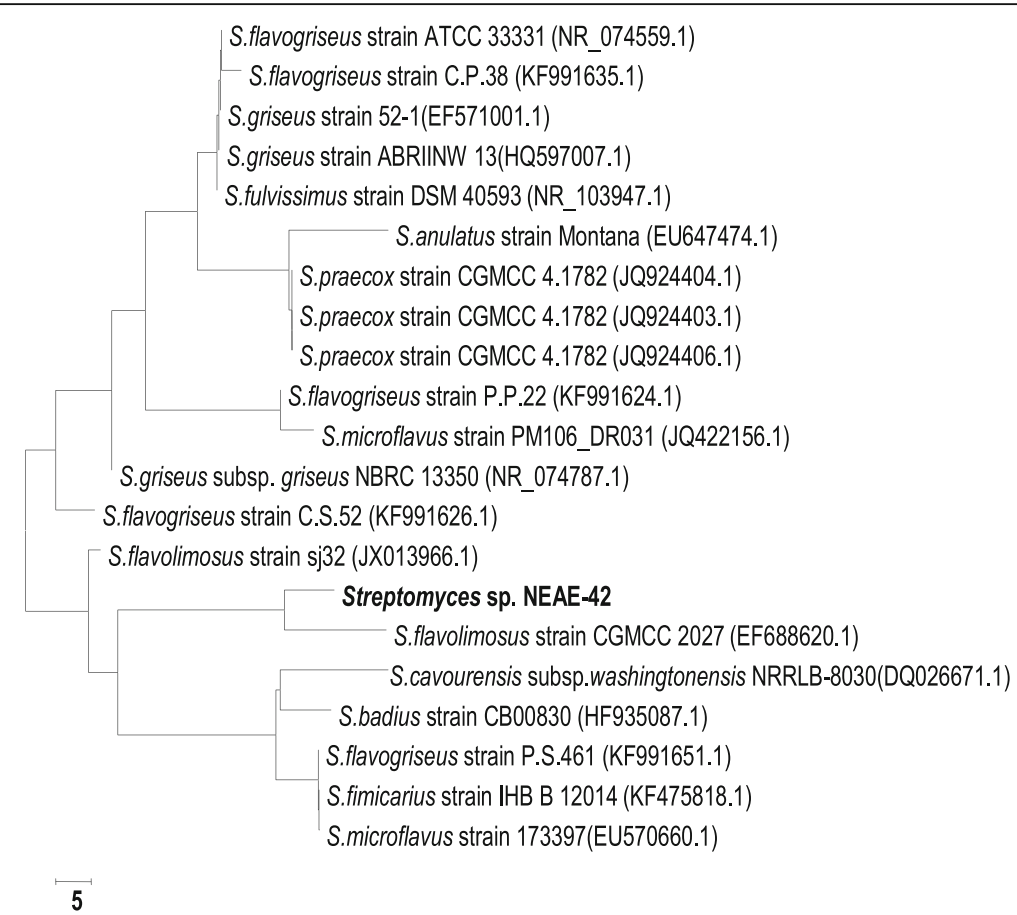

Fig. 3 Neighbour-joining phylogenetic tree based on 165 rRNA gene sequences, showing the relationships between strain NEAE-42 and related species of the genus Streptomyces. Bar, 5 substitution per nucleotide position

glucose, peptone, $\left(\mathrm{NH}_{4}\right)_{2} \mathrm{SO}_{4}, \mathrm{~K}_{2} \mathrm{HPO}_{4}, \mathrm{MgSO}_{4}, \mathrm{FeSO}_{4}$, incubation time and agitation speed affect positively cholesterol oxidase production, where the other five variables named yeast extract, $\mathrm{NaCl}$, temperature, inoculum size and $\mathrm{pH}$ affect negatively cholesterol oxidase production. The variables with positive effect were fixed at high level and the variables which exerted a negative effect on cholesterol oxidase production were maintained at low level for further optimization by a central composite design.

The Pareto chart illustrates the order of significant effects of the variables affecting cholesterol oxidase production in Plackett-Burman experimental design (Fig. 4b). It displays the absolute values of the effects, and draws a reference line on the chart. Any effect that extends past this reference line is potentially important.

The percentages of contributions of the variables are given in Table 5 . The results revealed that inoculum size, $\left(\mathrm{NH}_{4}\right)_{2} \mathrm{SO}_{4}, \mathrm{pH}$ and cholesterol are the most contributing variables with 15.323, 13.909, 12.521 and $12.293 \%$; respectively.

The analysis of variance (ANOVA) of the experimental design was calculated, and the sum of square, mean square, $F$-value, $t$-value, $P$-value and confidence level are given in Table 6 . The significance of the model was calculated by the $P$-value. The $P$-value (probability value) serves as a tool for checking the significance of each of the parameter. The model $F$-value of 101.19 and $P$-value of 0.0098 implies that the model is significant. There is only a $0.98 \%$ chance that a "Model F-Value" this large could occur due to noise. Values of "Prob $>F$ " ( $P$-value $)$ less than 0.05 indicate model terms are significant.

The data revealed that, nine variables (temperature, incubation time, inoculum size, $\mathrm{pH}$, glucose, cholesterol, yeast extract, peptone and $\left.\left(\mathrm{NH}_{4}\right)_{2} \mathrm{SO}_{4}\right)$ were found to significantly affect cholesterol oxidase production while the remaining six variables (agitation speed, starch, $\mathrm{K}_{2} \mathrm{HPO}_{4}, \mathrm{NaCl}, \mathrm{MgSO}_{4} .7 \mathrm{H}_{2} \mathrm{O}$ and $\mathrm{FeSO}_{4} .7 \mathrm{H}_{2} \mathrm{O}$ ) have not significant effect on the cholesterol oxidase production (Table 6). In this connection the analysis showed that, inoculum size $(C)$ with a probability value of 0.0026 was determined to be the most significant factor affecting cholesterol oxidase production by Streptomyces cavourensis strain NEAE-42 at 99.74\% confidence followed by $\left(\mathrm{NH}_{4}\right)_{2} \mathrm{SO}_{4}(\mathrm{~L})(P$-value $=0.0031), \mathrm{pH}(\mathrm{E})$ $(P$-value $=0.0039)$ and cholesterol $(\mathrm{H})(P$-value $=0.004)$, the lower probability values indicate the more significant variables affecting cholesterol oxidase production. Also, it was clear that among the four variables, only inoculum size exerted a negative effects, whereas the other variables $\left(\mathrm{pH}, \quad\left(\mathrm{NH}_{4}\right)_{2} \mathrm{SO}_{4}\right.$ and cholesterol) exerted positive effect on cholesterol oxidase production, which means that the increase in the concentrations of $\mathrm{pH}$ value, $\left(\mathrm{NH}_{4}\right)_{2} \mathrm{SO}_{4}$ and cholesterol concentration and 
Table 4 Twenty-trial Plackett-Burman experimental design for evaluation of independent variables with coded values along with the observed cholesterol oxidase activity

\begin{tabular}{|c|c|c|c|c|c|c|c|c|c|c|c|c|c|c|c|c|c|c|c|c|c|c|c|}
\hline \multirow[t]{2}{*}{ Std } & \multirow{2}{*}{$\begin{array}{l}\text { Run } \\
\text { no. }\end{array}$} & \multicolumn{19}{|c|}{ Coded levels of independent variables } & \multicolumn{2}{|c|}{ Cholesterol oxidase activity $(\mathrm{U} / \mathrm{mL})$} & \multirow[t]{2}{*}{ Residuals } \\
\hline & & A & $\mathrm{B}$ & $C$ & $\mathrm{D}$ & $E$ & $\mathrm{~F}$ & G & $\mathrm{H}$ & J & K & $\mathrm{L}$ & M & $\mathrm{N}$ & $\mathrm{O}$ & $\mathrm{P}$ & Dummy 1 & Dummy 2 & Dummy 3 & Dummy 4 & Actual value & Predicted value & \\
\hline 15 & 1 & 1 & 1 & 1 & -1 & 1 & -1 & 1 & -1 & -1 & -1 & -1 & 1 & 1 & -1 & 1 & 1 & -1 & -1 & 1 & 0.397 & 0.297 & 0.100 \\
\hline 6 & 2 & -1 & -1 & 1 & 1 & -1 & 1 & 1 & -1 & -1 & 1 & 1 & 1 & 1 & -1 & 1 & -1 & 1 & -1 & -1 & 1.522 & 1.622 & -0.100 \\
\hline 4 & 3 & 1 & 1 & -1 & 1 & 1 & -1 & -1 & 1 & 1 & 1 & 1 & -1 & 1 & -1 & 1 & -1 & -1 & -1 & -1 & 6.910 & 6.907 & 0.003 \\
\hline 3 & 4 & 1 & -1 & 1 & 1 & -1 & -1 & 1 & 1 & 1 & 1 & -1 & 1 & -1 & 1 & -1 & -1 & -1 & -1 & 1 & 1.267 & 1.263 & 0.003 \\
\hline 7 & 5 & -1 & -1 & -1 & 1 & 1 & -1 & 1 & 1 & -1 & -1 & 1 & 1 & 1 & 1 & -1 & 1 & -1 & 1 & -1 & 6.000 & 5.900 & 0.100 \\
\hline 17 & 6 & -1 & 1 & 1 & 1 & 1 & -1 & 1 & -1 & 1 & -1 & -1 & -1 & -1 & 1 & 1 & -1 & 1 & 1 & -1 & 1.080 & 1.180 & -0.100 \\
\hline 18 & 7 & -1 & -1 & 1 & 1 & 1 & 1 & -1 & 1 & -1 & 1 & -1 & -1 & -1 & -1 & 1 & 1 & -1 & 1 & 1 & 2.325 & 2.225 & 0.100 \\
\hline 8 & 8 & -1 & -1 & -1 & -1 & 1 & 1 & -1 & 1 & 1 & -1 & -1 & 1 & 1 & 1 & 1 & -1 & 1 & -1 & 1 & 1.953 & 2.053 & -0.100 \\
\hline 14 & 9 & 1 & 1 & -1 & 1 & -1 & 1 & -1 & -1 & -1 & -1 & 1 & 1 & -1 & 1 & 1 & -1 & -1 & 1 & 1 & 2.011 & 2.008 & 0.003 \\
\hline 19 & 10 & 1 & -1 & -1 & 1 & 1 & 1 & 1 & -1 & 1 & -1 & 1 & -1 & -1 & -1 & -1 & 1 & 1 & -1 & 1 & 2.260 & 2.263 & -0.003 \\
\hline 20 & 11 & -1 & -1 & -1 & -1 & -1 & -1 & -1 & -1 & -1 & -1 & -1 & -1 & -1 & -1 & -1 & -1 & -1 & -1 & -1 & 0.690 & 0.687 & 0.003 \\
\hline 2 & 12 & -1 & 1 & 1 & -1 & -1 & 1 & 1 & 1 & 1 & -1 & 1 & -1 & 1 & -1 & -1 & -1 & -1 & 1 & 1 & 0.490 & 0.487 & 0.003 \\
\hline 9 & 13 & 1 & -1 & -1 & -1 & -1 & 1 & 1 & -1 & 1 & 1 & -1 & -1 & 1 & 1 & 1 & 1 & -1 & 1 & -1 & 0.200 & 0.100 & 0.100 \\
\hline 16 & 14 & 1 & 1 & 1 & 1 & -1 & 1 & -1 & 1 & -1 & -1 & -1 & -1 & 1 & 1 & -1 & 1 & 1 & -1 & -1 & 0.000 & 0.003 & -0.003 \\
\hline 10 & 15 & -1 & 1 & -1 & -1 & -1 & -1 & 1 & 1 & -1 & 1 & 1 & -1 & -1 & 1 & 1 & 1 & 1 & -1 & 1 & 6.600 & 6.603 & -0.003 \\
\hline 12 & 16 & -1 & 1 & -1 & 1 & -1 & -1 & -1 & -1 & 1 & 1 & -1 & 1 & 1 & -1 & -1 & 1 & 1 & 1 & 1 & 1.667 & 1.670 & -0.003 \\
\hline 1 & 17 & 1 & 1 & -1 & -1 & 1 & 1 & 1 & 1 & -1 & 1 & -1 & 1 & -1 & -1 & -1 & -1 & 1 & 1 & -1 & 4.787 & 4.887 & -0.100 \\
\hline 13 & 18 & 1 & -1 & 1 & -1 & 1 & -1 & -1 & -1 & -1 & 1 & 1 & -1 & 1 & 1 & -1 & -1 & 1 & 1 & 1 & 2.076 & 2.176 & -0.100 \\
\hline 5 & 19 & -1 & 1 & 1 & -1 & 1 & 1 & -1 & -1 & 1 & 1 & 1 & 1 & -1 & 1 & -1 & 1 & -1 & -1 & -1 & 3.497 & 3.397 & 0.100 \\
\hline 11 & 20 & 1 & -1 & 1 & -1 & -1 & -1 & -1 & 1 & 1 & -1 & 1 & 1 & -1 & -1 & 1 & 1 & 1 & 1 & -1 & 0.807 & 0.810 & -0.003 \\
\hline
\end{tabular}


Table 5 Regression coefficients, estimated effect and \% of contribution for cholesterol oxidase production by Streptomyces cavourensis strain NEAE-42 using Plackett-Burman design

\begin{tabular}{lrrl}
\hline Term & Coefficient & Effect & \% Contribution \\
\hline Intercept & 2.327 & 4.654 & \\
A & -0.256 & -0.511 & 3.991 \\
B & 0.417 & 0.834 & 6.513 \\
C & -0.981 & -1.962 & 15.323 \\
D & 0.177 & 0.355 & 2.770 \\
E & 0.802 & 1.603 & 12.521 \\
F & -0.422 & -0.845 & 6.598 \\
G & 0.133 & 0.267 & 2.083 \\
H & 0.787 & 1.574 & 12.293 \\
J & -0.314 & -0.628 & 4.903 \\
K & 0.758 & 1.516 & 11.842 \\
L & 0.890 & 1.781 & 13.909 \\
M & 0.064 & 0.128 & 0.997 \\
N & -0.205 & -0.411 & 3.209 \\
O & 0.141 & 0.283 & 2.210 \\
P & 0.054 & 0.107 & 0.838 \\
\hline
\end{tabular}

decrease in inoculum size could exert positive effect on cholesterol oxidase production.

The $\mathrm{R}^{2}$ values provide a measure of how much variability in the observed response values can be explained by the experimental variables. The $R^{2}$ value is always between 0 and 1 . When $R^{2}$ is closer to the 1 , the model is stronger and better to predict the response [36]. The value of the determination coefficient $\left(R^{2}\right)$ was found to be 0.9988 indicates that $99.88 \%$ of the variability in cholesterol oxidase production could be explained by the independent variables used in the study and only $0.12 \%$ of the total variations are not explained by these variables. The adjusted $R^{2}(0.9890)$ is also very high that indicates that the model is very significant [37]. The "Pred R-Squared" of 0.8839 is in reasonable agreement with the "Adj R-Squared" of 0.9890. This indicated a good adjustment between the experimental and predicted values. "Adeq Precision" measures the signal to noise ratio. A ratio greater than 4 is desirable. Our ratio of 32.511 indicates an adequate signal.

A lower value of the coefficient of variation \% (CV \% $=9.6187 \%$ ) indicates a greater reliability of the experimental performance. The predicted residual sum of squares (PRESS) is a measure of how well the model fits each point in the design. The smaller the PRESS statistic, the better the model fits the data points. Our value of PRESS is 10.0187 . The model shows standard deviation and mean value of 0.2238 and 2.3269 , respectively.
The first order polynomial equation was derived after performing regression analysis on the results and representing cholesterol oxidase production as a function of the independent variables to obtain the optimum response. By neglecting the insignificant variables, the following regression equation in terms of coded variables was obtained:

$$
\begin{aligned}
\mathrm{Y}_{(\text {Cholesterol oxidase activity })=} & +2.33-0.26 \mathrm{~A}+0.42 \mathrm{~B}-0.98 \mathrm{C} \\
& +0.18 \mathrm{D}+0.80 \mathrm{E}-0.42 \mathrm{~F} \\
& +0.13 \mathrm{G}+0.79 \mathrm{H}-0.31 \mathrm{~J} \\
& +0.76 \mathrm{~K}+0.89 \mathrm{~L} \\
& +0.064 \mathrm{M}-0.21 \mathrm{~N}+0.14 \mathrm{O} \\
& +0.054 \mathrm{P}-0.18 \mathrm{~S}-0.22 \mathrm{~T}
\end{aligned}
$$

Where $\mathrm{Y}$ is cholesterol oxidase production, and $\mathrm{A}$, $\mathrm{B}, \mathrm{C}, \mathrm{E}, \mathrm{F}, \mathrm{H}, \mathrm{J}, \mathrm{K}$ and $\mathrm{L}$ are temperature, incubation time, inoculum size, $\mathrm{pH}$, glucose, cholesterol, yeast extract, peptone and $\left(\mathrm{NH}_{4}\right)_{2} \mathrm{SO}_{4}$ respectively. The coefficient of each variable represents the effect extent of these variables on cholesterol oxidase production.

On the basis of $t$ Stat (Table 6), cholesterol concentration, $\mathrm{pH}$ and $\left(\mathrm{NH}_{4}\right)_{2} \mathrm{SO}_{4}$ were chosen for further optimization using central composite design experiments (CCD), since these factors had the most positive significant effects on cholesterol oxidase production.

\section{Model adequacy checking}

As observed from Box-Cox plot (Fig. 5), the blue line indicates the current transformation (Lambda $=1$ ) and the green line indicates the best lambda value $(=0.77)$, while the red lines indicate the minimum and maximum $95 \%$ confidence interval values ( 0.57 and 0.98 respectively). So that the model is well fit to the experimental data obtained and well satisfies the assumptions of the analysis of variance.

In a confirmatory experiment, to evaluate the accuracy of Plackett-Burman, a medium of the following composition: Temperature $30{ }^{\circ} \mathrm{C}$; incubation time 7 days; inoculum size 2(\%, v/v); agitation speed $200 \mathrm{rpm} ; \mathrm{pH} 8$; glucose $10 \mathrm{~g} / \mathrm{L}$; starch $10 \mathrm{~g} / \mathrm{L}$; cholesterol $2 \mathrm{~g} / \mathrm{L}$; yeast extract $4 \mathrm{~g} / \mathrm{L}$; peptone $5 \mathrm{~g} / \mathrm{L} ;\left(\mathrm{NH}_{4}\right)_{2} \mathrm{SO}_{4} 8 \mathrm{~g} / \mathrm{L} ; \mathrm{K}_{2} \mathrm{HPO}_{4} 1 \mathrm{~g} / \mathrm{L} ; \mathrm{NaCl} 0.5 \mathrm{~g} / \mathrm{L} ;$ $\mathrm{MgSO}_{4} .7 \mathrm{H}_{2} \mathrm{O} \quad 0.5 \mathrm{~g} / \mathrm{L} ; \quad \mathrm{FeSO}_{4} .7 \mathrm{H}_{2} \mathrm{O} \quad 0.02 \mathrm{~g} / \mathrm{L}$, which expected to be optimum gives cholesterol oxidase activity of $6.732 \mathrm{U} / \mathrm{mL}$ which is higher than result obtained from the basal medium before applying Plackett Burman by more than two times $(3.31 \mathrm{U} / \mathrm{mL})$.

Various compounds, such as cholesterol, yeast extract [10], yeast extract, potato starch, peptone and malt extract [38] have been recorded to be substrates for an enhanced cholesterol oxidase production. Cholesterol is utilized widely by different microorganisms as a carbon 
Table 6 Regression statistics and analysis of variance (ANOVA) for the experimental results of Plackett-Burman design used for cholesterol oxidase production by Streptomyces cavourensis strain NEAE-42

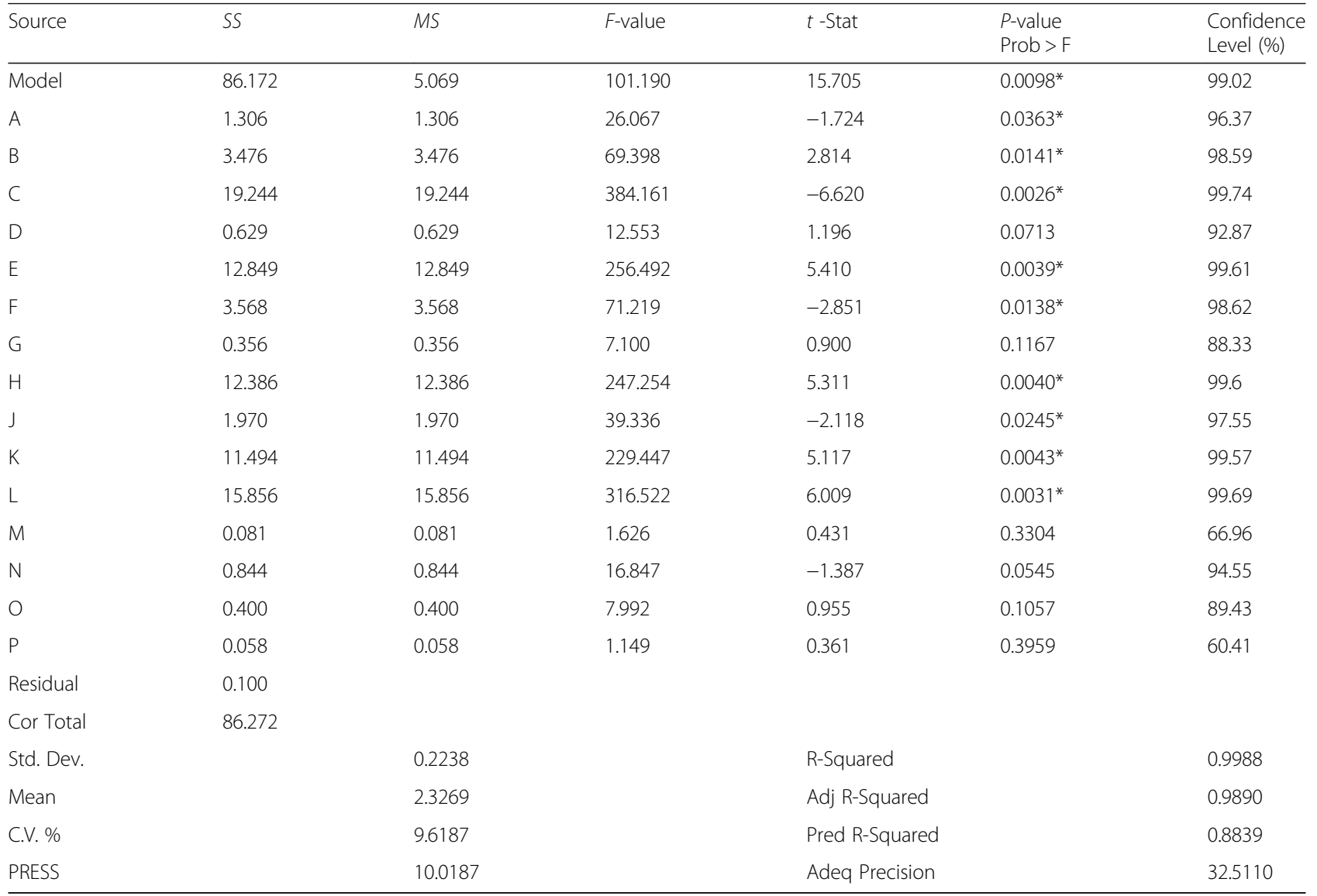

SS - sum of squares, MS- mean square, F: Fishers's function, $P$ : Level of significance, PRESS the predicted residual sum of squares, CV \%-the coefficient of variation $\%$ *Significant values

and energy source [12]. Different microorganisms such as Brevibacterium, Corynebacterium, Arthrobacter, Nocardia, Mycobacterium, and Streptomyces have the ability to degrade cholesterol. The first step of microbial assimilation of cholesterol is the oxidation of the $3 \beta$ - hydroxyl group by cholesterol oxidase [39]. Therefore, cholesterol assimilating microorganisms are generally considered to produce cholesterol oxidases. Yehia et al. [40] reported that the growth and assimilation of cholesterol by the tested bacterial isolates were affected greatly by concentration of cholesterol used in the fermentation medium, whereas the maximum percentage of cholesterol assimilation (80.2\%) by the Enterococcus hirae strain was achieved at $1 \mathrm{~g} / \mathrm{L}$ of the added cholesterol and maximal assimilation of cholesterol by Streptomyces fradiae [10] and Rhodococcus erythropolis ATCC 25544 [41] was obtained when used $2 \mathrm{~g} / \mathrm{L}$.

The $\mathrm{pH}$ of the cultivation medium is very important for the microbial growth and metabolism, and hence, for the production of metabolites. The $\mathrm{pH}$ may have a direct effect on the cell, or it may indirectly affect it by varying the dissociation degree of the medium components [42]. The $\mathrm{pH}$ value of the culture medium plays a critical role in the optimal physiological performance of the cells and the transport of various nutrient components across the cell membrane, and the cholesterol assimilation is affected by a change in the $\mathrm{pH}$ value of the media. It was previously reported that the optimal $\mathrm{pH}$ values for cholesterol assimilation are 7.2 for Streptomyces fradiae [10] and 6.75 for Rhodococcus erythropolis ATCC 25544 [41]. Moreover, it was found that, optimal $\mathrm{pH}$ value required to attain maximum growth and assimilation of cholesterol (80.2 \%) in the liquid medium by Enterococcus hirae was $\mathrm{pH} 7.0$ using $0.2 \mathrm{M}$ acetate buffer and $0.2 \mathrm{M}$ phosphate buffer [40]. Solingen et al. [43] reported that an alkaline novel Streptomyces species isolated from east african soda lakes have an optimal $\mathrm{pH} 8$.

Voelker and Altaba [44] estimated the role of different organic and inorganic nitrogen sources for growth and production of secondary metabolite from a Streptomycetes. In general, cholesterol oxidase production was enhanced far more by using organic nitrogen than inorganic nitrogen. This may be due to organic nitrogen contains most types of growth factors and amino acids important for the bacterial 

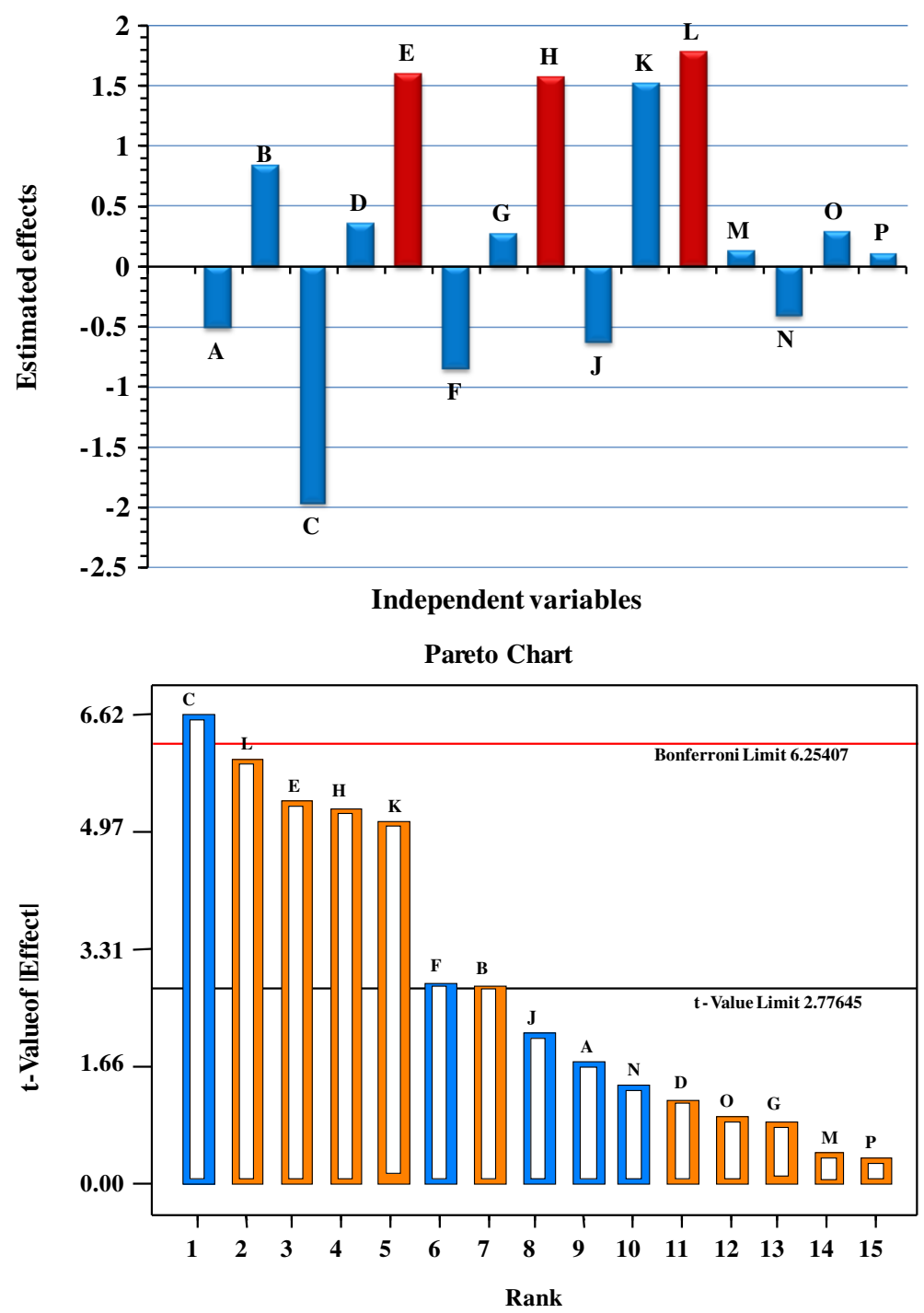

Fig. 4 a Effect of independent variables on cholesterol oxidase production by Streptomyces cavourensis strain NEAE-42 using Plackett-Burman design (The red color represent the most significant positive independent variables affecting enzyme production); $\mathbf{b}$ Pareto chart illustrates the order and significance of the variables affecting cholesterol oxidase production by Streptomyces cavourensis strain NEAE-42 using Plackett-Burman design (the blue colors represent negative effects and the orange color represent positive effects)

growth and could be metabolized by cells directly, consequently enhancing cholesterol oxidase production [45]. Sabry [46] reported that ammonium sulphate, sodium nitrate and ammonium nitrate are the best nitrogen sources used for cholesterol assimilation by Pseudonocardia compacta S-39. Ammonium salts have shown the highest effect on cholesterol oxidase production by Arthrobacter simplex [47]. The cell mass obtained using the growth stimulating nitrogen sources, namely yeast extract and $\left(\mathrm{NH}_{4}\right)_{2} \mathrm{HPO}_{4}$, supports the cholesterol oxidase accumulation as induced by the cholesterol substrate in the cell wall [48]. Among inorganic and organic nitrogen sources, it was revealed that yeast extract had more influence on cholesterol oxidase production than $\left(\mathrm{NH}_{4}\right)_{2} \mathrm{SO}_{4}$ (inorganic nitrogen source) [49]. According to Lee et al. [50], study on Rhodococcus equi no. 23 showed that yeast extract at $0.4-0.5 \% \mathrm{w} / \mathrm{v}$ was the best nitrogen source for cholesterol oxidase production. In a similar study, Rhodococcus equi $2 \mathrm{C}$ showed maximum production of cholesterol oxidase with yeast extract at $0.3 \% \mathrm{w} / \mathrm{v}[10]$.

\section{Statistical optimization of fermentation process variables for cholesterol oxidase production using central composite design (CCD)}

The results indicate the effectiveness of the PlackettBurman design in identifying the factors with a positive 


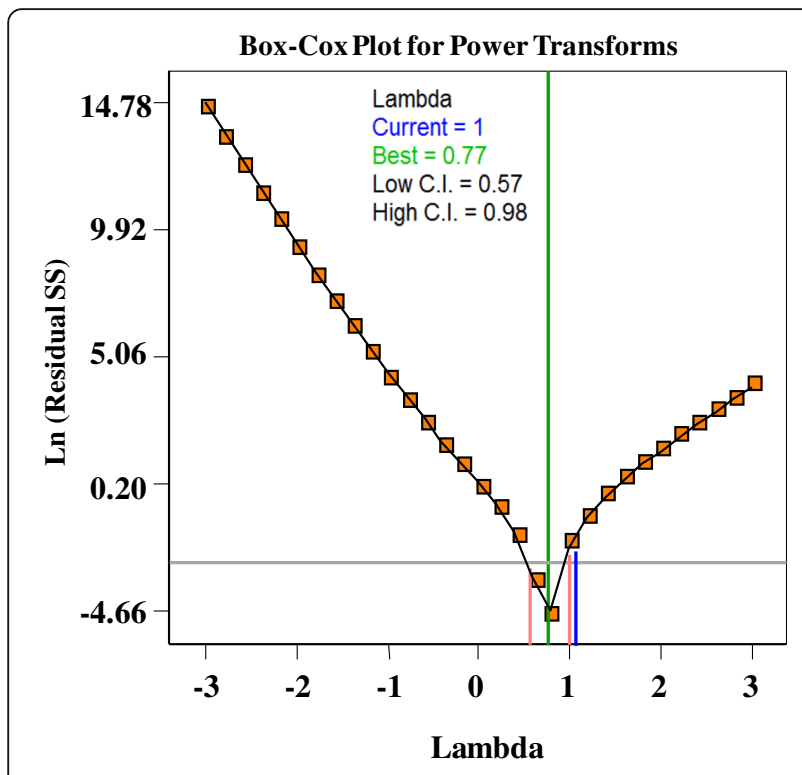

Fig. 5 Box- Cox plot of model transformations

significant influence on the cholesterol oxidase production. As Plackett-Burman design is inappropriate to study the mutual interaction of process variables, therefore the level of significant factors needed further optimization. Thereafter the exact optimal values for the individual significant factors were determined using central composite design experiments. The significant variables with positive effect were fixed at high level. The variables which exerted a negative effect on cholesterol oxidase production were maintained in all trials at their low level for further optimization by central composite design; other insignificant variables were set at their low level of Placket-Burman design design as the following: Temperature $30{ }^{\circ} \mathrm{C}$; incubation time 7 days; inoculum size $2(\%, \mathrm{v} / \mathrm{v})$; agitation speed $150 \mathrm{rpm}$; glucose $10 \mathrm{~g} / \mathrm{L}$; starch $7 \mathrm{~g} / \mathrm{L}$; yeast extract $4 \mathrm{~g} / \mathrm{L}$; peptone $5 \mathrm{~g} / \mathrm{L} ; \mathrm{K}_{2} \mathrm{HPO}_{4} 0.5 \mathrm{~g} / \mathrm{L} ; \mathrm{NaCl} 0.5 \mathrm{~g} / \mathrm{L} ; \mathrm{MgSO}_{4} .7 \mathrm{H}_{2} \mathrm{O}$ $0.2 \mathrm{~g} / \mathrm{L}$.

Placket-Burman design results revealed that, $\mathrm{pH}\left(\mathrm{X}_{1}\right)$, cholesterol concentration $\left(\mathrm{X}_{2}\right)$, and $\left(\mathrm{NH}_{4}\right)_{2} \mathrm{SO}_{4}\left(\mathrm{X}_{3}\right)$ were the most significant positive independent variables affecting cholesterol oxidase production, thus they were selected for further optimization using five level central composite design (CCD). Table 7 shows the three independent variables and their concentrations at different coded and actual levels of the variables employed in the design matrix.

Central composite design matrix and responses (experimental and predicted cholesterol oxidase) for the 20 runs of the design are presented in Table 7, which shows considerable variation in the amount of cholesterol oxidase activity. Based on the experimental data obtained; cholesterol oxidase activity ranged from 6.362 to $20.521 \mathrm{U} / \mathrm{mL}$, the highest levels of cholesterol oxidase activity were obtained in runs $6,14,15,16,17$ and 20 (center points) with values of 20.403, 20.348, 20.424, $20.279,20.521$ and $20.376 \mathrm{U} / \mathrm{mL}$ respectively, where $\mathrm{pH} 8$, cholesterol concentration $3 \mathrm{~g} / \mathrm{L},\left(\mathrm{NH}_{4}\right)_{2} \mathrm{SO}_{4} 8 \mathrm{~g} / \mathrm{L}$ were used, while the minimum cholesterol oxidase activity was observed in run number 1 where $\mathrm{pH} 8$, cholesterol concentration $3 \mathrm{~g} / \mathrm{L},\left(\mathrm{NH}_{4}\right)_{2} \mathrm{SO}_{4} 10 \mathrm{~g} / \mathrm{L}$ were used. In Table 7 , the observed values for cholesterol oxidase activity is compared with the predicted values from the model.

The data were analyzed using Design Expert ${ }^{\circ} 7.0$ for Windows to perform statistical analysis. The determination coefficient $\left(\mathrm{R}^{2}\right)$ of the model was 0.9794 (Table 8) indicating that $97.94 \%$ of variability in the production of cholesterol oxidase was attributed to the selected independent variables and only $2.06 \% \%$ of the total variance could not be explained by the model. The highest $R^{2}$ value showed the good agreement between the experimental results and the predicted values by the model [51]. If $\mathrm{R}^{2}$-value of the regression model is higher than 0.9 , it was considered as having a very high correlation [52]. Therefore, the present $R^{2}$-value reflected a very good fit between the observed and predicted responses, and implied that the model is reliable for cholesterol oxidase production in the current study. The "Pred R-Squared" of 0.8434 is in reasonable agreement with the "Adj RSquared" of 0.9608 . This indicated a good correlation between the predicted and observed values. "Adeq Precision" measures the signal to noise ratio. A ratio greater than 4 is desirable. Our ratio of 23.224 indicates an adequate signal. Usually, the higher value of the coefficient of variation \% (CV \%) indicated the lower reliability of the experiment, in the present study, a lower value of C.V. (5.7815) indicated a better reliability of the experimental results [53]. The predicted residual sum of squares (PRESS) is a measure of how well the model fits each point in the design. The smaller the PRESS statistic indicates better model fits for the data points. Our value of PRESS is 58.33. The model shows standard deviation and mean value of 0.876 and 15.16 , respectively (Table 8 ). The positive coefficients for $\mathrm{X}_{1} \mathrm{X}_{2}$ (Table 8) indicate that the interaction effect between the two variables increase cholesterol oxidase production, while negative coefficients indicate that the interaction effect between the two variables decrease in cholesterol oxidase production.

The model adequacy was checked using analysis of variance (ANOVA) which was tested using Fisher's statistical analysis and the results are shown in 
Table 7 Central composite design representing the response of cholesterol oxidase production by Streptomyces cavourensis strain NEAE-42 as influenced by initial pH $\left(X_{1}\right)$, cholesterol $\left(X_{2}\right)$ and ammonium sulphate $\left(X_{3}\right)$ along with the predicted cholesterol oxidase production and residuals and the levels of variables with actual factor levels corresponding to coded factor levels

\begin{tabular}{|c|c|c|c|c|c|c|c|c|}
\hline \multirow[t]{2}{*}{ Std } & \multirow[t]{2}{*}{ Run } & \multirow[t]{2}{*}{ Type } & \multicolumn{3}{|c|}{ Variables } & \multicolumn{2}{|c|}{ Cholesterol oxidase activity $(\mathrm{U} / \mathrm{mL})$} & \multirow[t]{2}{*}{ Residuals } \\
\hline & & & $x_{1}$ & $x_{2}$ & $x_{3}$ & Experimental & Predicted & \\
\hline 14 & 1 & Axial & 0 & 0 & 1.68 & 6.362 & 5.970 & 0.392 \\
\hline 11 & 2 & Axial & 0 & -1.68 & 0 & 18.184 & 17.893 & 0.290 \\
\hline 7 & 3 & Factorial & -1 & 1 & 1 & 10.612 & 10.674 & -0.062 \\
\hline 3 & 4 & Factorial & -1 & 1 & -1 & 16.506 & 15.551 & 0.955 \\
\hline 4 & 5 & Factorial & 1 & 1 & -1 & 15.367 & 14.300 & 1.067 \\
\hline 19 & 6 & Center & 0 & 0 & 0 & 20.403 & 20.365 & 0.038 \\
\hline 5 & 7 & Factorial & -1 & -1 & 1 & 13.655 & 14.060 & -0.405 \\
\hline 2 & 8 & Factorial & 1 & -1 & -1 & 13.630 & 12.906 & 0.724 \\
\hline 12 & 9 & Axial & 0 & 1.68 & 0 & 14.992 & 16.218 & -1.226 \\
\hline 9 & 10 & Axial & -1.68 & 0 & 0 & 15.492 & 15.476 & 0.016 \\
\hline 10 & 11 & Axial & 1.68 & 0 & 0 & 11.401 & 12.353 & -0.951 \\
\hline 1 & 12 & Factorial & -1 & -1 & -1 & 14.431 & 14.408 & 0.023 \\
\hline 6 & 13 & Factorial & 1 & -1 & 1 & 11.303 & 11.596 & -0.293 \\
\hline 17 & 14 & Center & 0 & 0 & 0 & 20.348 & 20.365 & -0.017 \\
\hline 18 & 15 & Center & 0 & 0 & 0 & 20.424 & 20.365 & 0.059 \\
\hline 20 & 16 & Center & 0 & 0 & 0 & 20.279 & 20.365 & -0.086 \\
\hline 16 & 17 & Center & 0 & 0 & 0 & 20.521 & 20.365 & 0.156 \\
\hline 13 & 18 & Axial & 0 & 0 & -1.68 & 9.845 & 11.172 & -1.327 \\
\hline 8 & 19 & Factorial & 1 & 1 & 1 & 9.101 & 8.462 & 0.639 \\
\hline 15 & 20 & Center & 0 & 0 & 0 & 20.376 & 20.365 & 0.011 \\
\hline Level & & $\mathrm{pH}$ & \multicolumn{3}{|c|}{ Cholesterol (g/L) } & \multicolumn{2}{|c|}{ Ammonium sulphate (g/L) } & \\
\hline-1.68 & & 6 & \multicolumn{3}{|l|}{1} & \multicolumn{2}{|l|}{5} & \\
\hline-1 & & 7 & \multicolumn{3}{|l|}{2} & \multicolumn{2}{|l|}{6} & \\
\hline 0 & & 8 & \multicolumn{3}{|l|}{3} & \multicolumn{2}{|l|}{8} & \\
\hline 1 & & 9 & \multicolumn{3}{|l|}{4} & \multicolumn{2}{|l|}{9} & \\
\hline 1.68 & & 10 & \multicolumn{3}{|l|}{5} & \multicolumn{2}{|l|}{10} & \\
\hline
\end{tabular}

Table 9. The Model F-value of 52.77 indicate the model is significant. There is only a $0.01 \%$ chance that a "Model F-Value" this large could occur due to noise. Values of "Prob $>F$ " less than 0.05 indicate model terms are significant. In this case $X_{1}, X_{3}, X_{2}$ $\mathrm{X}_{3}, \mathrm{X}_{1}^{2}, \mathrm{X}_{2}^{2}, \mathrm{X}_{3}^{2}$ are significant model terms. Values greater than 0.1 indicate the model terms are not significant. The "Lack of Fit F-value" of 233.149 implies the Lack of Fit is significant. There is only a $0.01 \%$ chance that a "Lack of Fit $F$-value" this large could occur due to noise (Table 9).

The fit summary results are presented in Table 10, contributed to find an adequate type of response surface model. Quadratic model type was selected to be the proper model that fit the CCD of cholesterol oxidase production by Streptomyces cavourensis strain NEAE-42, where the results of fit summary showed that, the quadratic model is a highly significant with a very low probability value $\left[\left(P_{\text {model }}>F\right)<0.0001\right]$. The model summary statistics of the quadratic model showed the smallest standard deviation of 0.877 and the largest predicted and adjusted R-squared of 0.961 and 0.843 respectively.

A second-order polynomial model (Eq. 4) was proposed to calculate the optimum levels of $\mathrm{pH}$, cholesterol concentration and $\left(\mathrm{NH}_{4}\right)_{2} \mathrm{SO}_{4}$, to evaluate the relationship between cholesterol oxidase production and independent variables and to determine the maximum cholesterol oxidase production corresponding to the optimum levels of these variables. The second-order 
Table 8 Regression statistics of CCD for optimization of cholesterol oxidase production by Streptomyces cavourensis strain NEAE-42

\begin{tabular}{|c|c|c|c|c|}
\hline Factor & Coefficient estimate & Standard error & $95 \%$ Cl Low & $95 \%$ Cl High \\
\hline Intercept & 20.365 & 0.358 & 19.569 & 21.162 \\
\hline $\mathrm{X}_{1}$ (initial $\mathrm{pH}$ ) & -0.929 & 0.237 & -1.457 & -0.400 \\
\hline $\mathrm{X}_{2}$ (cholesterol) & -0.498 & 0.237 & -1.026 & 0.031 \\
\hline $\mathrm{X}_{3}$ (ammonium sulphate) & -1.547 & 0.237 & -2.075 & -1.018 \\
\hline$x_{1} x_{2}$ & 0.063 & 0.310 & -0.628 & 0.753 \\
\hline$x_{1} x_{3}$ & -0.240 & 0.310 & -0.931 & 0.450 \\
\hline$x_{2} x_{3}$ & -1.132 & 0.310 & -1.823 & -0.442 \\
\hline$x_{1}^{2}$ & -2.281 & 0.231 & -2.795 & -1.766 \\
\hline$x_{2}^{2}$ & -1.170 & 0.231 & -1.685 & -0.656 \\
\hline$x_{3}^{2}$ & -4.170 & 0.231 & -4.684 & -3.655 \\
\hline Std. Dev. & 0.8766 & \multicolumn{2}{|l|}{ R-Squared } & 0.9794 \\
\hline Mean & 15.1615 & \multicolumn{2}{|l|}{ Adj R-Squared } & 0.9608 \\
\hline C.V. $\%$ & 5.7815 & \multicolumn{2}{|l|}{ Pred R-Squared } & 0.8434 \\
\hline PRESS & 58.3337 & \multicolumn{2}{|l|}{ Adeq Precision } & 23.2242 \\
\hline C.V: Coefficient of variation & & & & \\
\hline
\end{tabular}

polynomial equation that defines predicted response $(\mathrm{Y})$ in terms of the independent variables $\left(\mathrm{X}_{1}, \mathrm{X}_{2}\right.$ and $\mathrm{X}_{3}$ ) was obtained:

$$
\begin{aligned}
\mathrm{Y}(\text { Cholesterol oxidase activity })= & +20.37-0.93 \mathrm{X}_{1}-0.50 \mathrm{X}_{2}-1.55 \mathrm{X}_{3} \\
& +0.063 \mathrm{X}_{1} \mathrm{X}_{2}-0.24 \mathrm{X}_{1} \mathrm{X}_{3}-1.13 \mathrm{X}_{2} \mathrm{X}_{3} \\
& -2.28 \mathrm{X}_{1}^{2}-1.17 \mathrm{X}_{2}^{2}-4.17 \mathrm{X}_{3}^{2}
\end{aligned}
$$

Where the $\mathrm{Y}$ is the predicted cholesterol oxidase activity, $\mathrm{pH}\left(\mathrm{X}_{1}\right)$, cholesterol concentration $\left(\mathrm{X}_{2}\right)$, and $\left(\mathrm{NH}_{4}\right)_{2} \mathrm{SO}_{4}\left(\mathrm{X}_{3}\right)$.

\section{Three dimensional plots}

The three dimensional response surface curves were plotted to understand the interaction of the variables and the optimal levels of each variable required for the optimal cholesterol oxidase production. Three dimensional plots for the combinations of the three variables $\left(\mathrm{X}_{1} \mathrm{X}_{2}, \mathrm{X}_{1} \mathrm{X}_{3}\right.$, and $\left.\mathrm{X}_{2} \mathrm{X}_{3}\right)$ were generated by plotting the response (cholesterol oxidase production) on Z-axis against two independent variables while keeping the other variable at its center point (shown in Figs. 6a-c).

\begin{tabular}{|c|c|c|c|c|c|}
\hline Source & Sum of Squares & $d f$ & Mean Square & F-value & $P$-value Prob $>F$ \\
\hline Model & 364.929 & 9 & 40.548 & 52.771 & $<0.0001^{*}$ \\
\hline $\mathrm{X}_{1}$ (initial $\mathrm{pH}$ ) & 11.778 & 1 & 11.778 & 15.328 & $0.0029^{*}$ \\
\hline $\mathrm{X}_{2}$ (cholesterol) & 3.386 & 1 & 3.386 & 4.406 & 0.0622 \\
\hline$x_{3}$ (ammonium sulphate) & 32.666 & 1 & 32.666 & 42.513 & $<0.0001^{*}$ \\
\hline$x_{1} x_{2}$ & 0.032 & 1 & 0.032 & 0.041 & 0.8432 \\
\hline$x_{1} x_{3}$ & 0.462 & 1 & 0.462 & 0.602 & 0.4558 \\
\hline$x_{2} x_{3}$ & 10.254 & 1 & 10.254 & 13.344 & $0.0044^{*}$ \\
\hline$X_{1}^{2}$ & 74.961 & 1 & 74.961 & 97.557 & $<0.0001^{*}$ \\
\hline$x_{2}^{2}$ & 19.730 & 1 & 19.730 & 25.677 & $0.0005^{*}$ \\
\hline$x_{3}^{2}$ & 250.574 & 1 & 250.574 & 326.109 & $<0.0001^{*}$ \\
\hline Residual & 7.684 & 10 & 0.768 & & \\
\hline Lack of Fit & 7.651 & 5 & 1.530 & 233.149 & $<0.0001^{*}$ \\
\hline Pure Error & 0.033 & 5 & 0.007 & & \\
\hline Cor Total & 372.613 & 19 & & & \\
\hline
\end{tabular}

Table 9 Analysis of variance (ANOVA) for CCD results used for optimizing cholesterol oxidase production by Streptomyces cavourensis strain NEAE-42 
Table 10 Fit summary for experimental data

\begin{tabular}{|c|c|c|c|c|c|}
\hline \multicolumn{6}{|l|}{ Sequential Model Sum of Squares } \\
\hline Source & Sum of Squares & $d f$ & Mean Square & F-value & $P$-value (Prob $>F$ ) \\
\hline Linear vs Mean & 47.829 & 3 & 15.943 & 0.785 & 0.5194 \\
\hline Two factors interaction (2FI) vs Linear & 10.748 & 3 & 3.583 & 0.148 & 0.9289 \\
\hline Quadratic vs 2FI & 306.352 & 3 & 102.117 & 132.900 & $<0.0001^{*}$ \\
\hline Residual & 2.226 & 6 & 0.371 & & \\
\hline \multicolumn{6}{|l|}{ Lack of Fit Tests } \\
\hline Source & Sum of Squares & $d f$ & Mean Square & F-value & $P$-value (Prob $>F$ ) \\
\hline Linear & 324.750 & 11 & 29.523 & 4498.259 & $<0.0001^{*}$ \\
\hline Two factors interaction (2FI) & 314.003 & 8 & 39.250 & 5980.409 & $<0.0001^{*}$ \\
\hline Quadratic & 7.651 & 5 & 1.530 & 233.149 & $<0.0001^{*}$ \\
\hline Pure Error & 0.033 & 5 & 0.007 & & \\
\hline \multicolumn{6}{|l|}{ Model Summary Statistics } \\
\hline Source & Standard deviation & R-Squared & Adjusted R-Squared & Predicted R-Squared & PRESS \\
\hline Linear & 4.505 & 0.128 & -0.035 & -0.277 & 475.939 \\
\hline Two factors interaction (2FI) & 4.915 & 0.157 & -0.232 & -0.826 & 680.540 \\
\hline Quadratic & 0.877 & 0.979 & 0.961 & 0.843 & 58.334 \\
\hline
\end{tabular}

$d f$ : degree of freedom, PRESS: sum of squares of prediction error

* Significant values

The 3D plot (Fig. 6a), showing the effects of initial $\mathrm{pH}\left(\mathrm{X}_{1}\right)$, and cholesterol $\left(\mathrm{X}_{2}\right)$ on cholesterol oxidase production. It can be seen that, when the initial $\mathrm{pH}$ increases, cholesterol oxidase production gradually increases, but further increase in initial $\mathrm{pH}$ above 7.5 leads to decrease in cholesterol oxidase production. It showed that lower and higher levels of cholesterol support relatively low levels of cholesterol oxidase activity; cholesterol oxidase activity was increased with increase in cholesterol concentration. The maximum cholesterol oxidase activity was attained at middle levels of cholesterol. Figure $6 \mathrm{~b}$ represents the cholesterol oxidase activity as a function of initial $\mathrm{pH}\left(\mathrm{X}_{1}\right)$, ammonium sulphate $\left(\mathrm{X}_{3}\right)$ by keeping cholesterol $\left(\mathrm{X}_{2}\right)$ at optimum value, the maximum cholesterol oxidase activity was attained at moderate levels of both initial $\mathrm{pH}$ and ammonium sulphate and further increase resulted in a gradual decrease in the cholesterol oxidase activity. In addition, the interaction between these variables were not significant, indicating that there is no significant correlation between each two variables and that they did not help much in increasing the production of cholesterol oxidase production. Figure $6 \mathrm{c}$ represents the cholesterol oxidase activity as a function of cholesterol $\left(\mathrm{X}_{2}\right)$, ammonium sulphate $\left(\mathrm{X}_{3}\right)$ by keeping initial $\mathrm{pH}\left(\mathrm{X}_{1}\right)$ at optimum value, the maximum cholesterol oxidase activity was attained at moderate levels of ammonium sulphate and further increase resulted in a gradual decrease in the cholesterol oxidase activity. It was observed that there is increasing in cholesterol oxidase activity with increasing cholesterol concentration, the maximum cholesterol oxidase activity was obtained at moderate levels and further increase resulted in a gradual decrease in the cholesterol oxidase activity. In addition, the interaction between these variables were significant, indicating that there is significant correlation between each two variables and that they help much in increasing the production of cholesterol oxidase activity.

\section{Model adequacy checking}

The normal probability plot is an important diagnostic tool which indicates whether the residuals follow a normality assumption, in which case the points will follow a straight line expect some scatter even with normal data. Figure 7 showed that, the normality assumption was satisfied as the residual plot approximated a long a straight line for cholesterol oxidase production, this indicates that the model was well fitted with the experimental results. As the residuals from the fitted model were normally distributed, all the major assumptions of the model had been validated.

\section{Validation of the model}

The model was validated by repeating the experiments under the optimized conditions, which resulted in the 


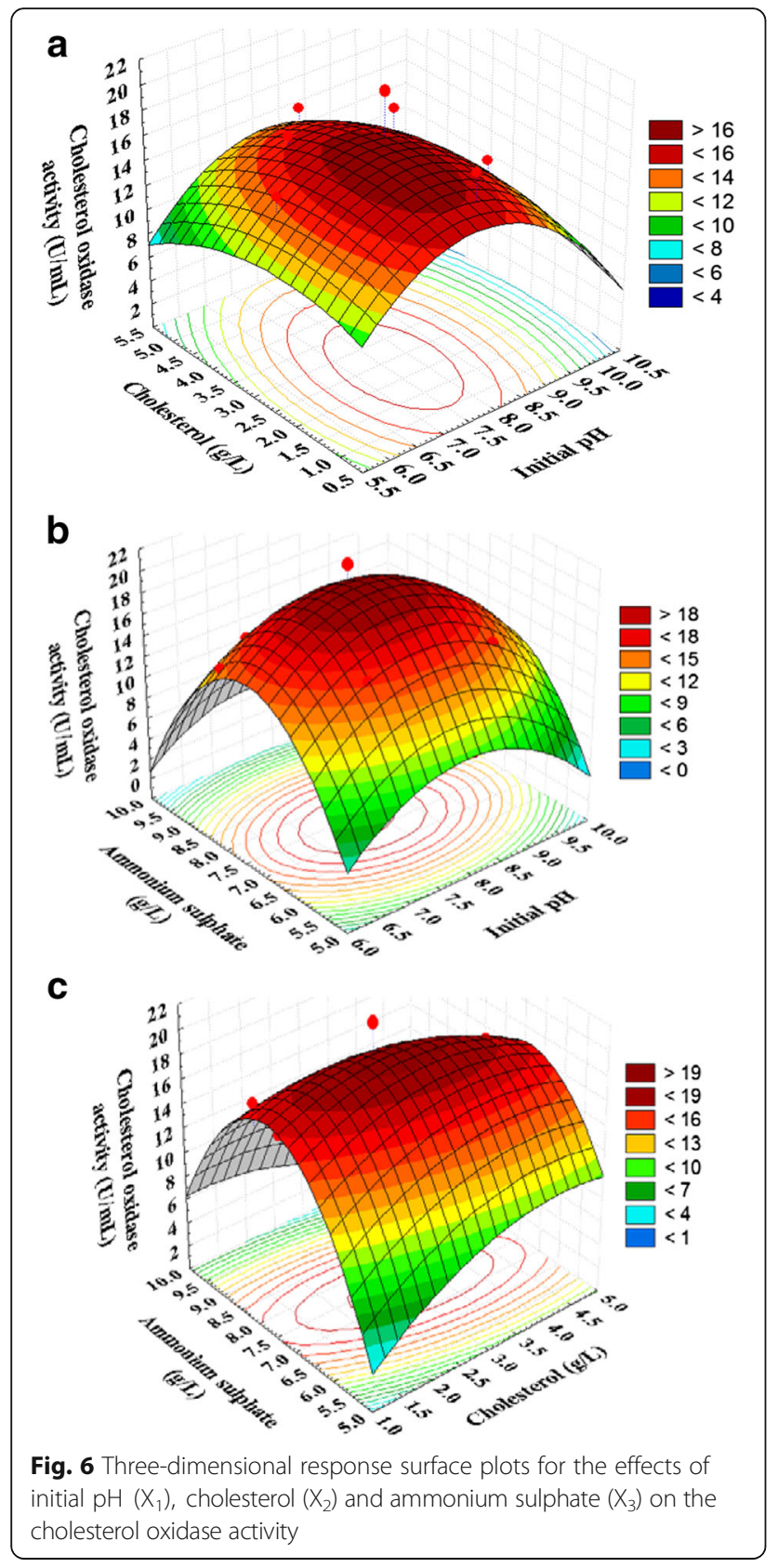

cholesterol oxidase production of $20.279 \mathrm{U} / \mathrm{mL}$ (predicted response $20.365 \mathrm{U} / \mathrm{mL}$ ), indicating a strong agreement between them and proving the validity of the model.

\section{Conclusion}

Little data has been reported in the literature on the optimization of cholesterol oxidase production by microorganisms using statistical methods. The level of cholesterol oxidase production obtained in our study

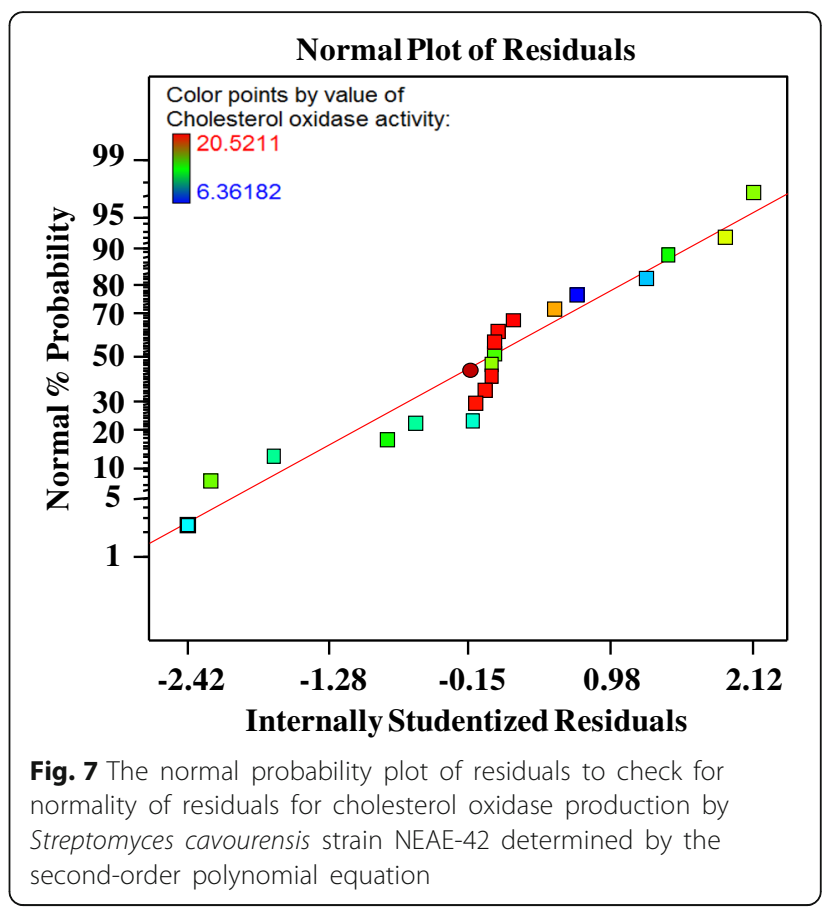

$(20.521 \mathrm{U} / \mathrm{mL})$ following the statistical method is higher than many of the reported values $[10,38,45]$.

\section{Abbreviations}

ANOVA: The analysis of variance; CCD: Central composite design; CV:

The coefficient of variation\%; HDL: High-density lipoprotein; HPLC: High performance liquid chromatography; LDL: Low-density lipoprotein; PB: Plackett-Burman; PCR: The polymerase chain reaction; PRESS: The predicted residual sum of squares

\section{Acknowledgments}

The authors would like to extend their sincere appreciation to the City for Scientific Research and Technological Applications, Alexandria, Egypt for funding this study.

\section{Funding}

City for Scientific Research and Technological Applications, Alexandria, Egypt.

\section{Availability of data and material}

The phylogenetic tree, sequence data and alignments used to produce the results displayed in Fig. 3 have been deposited in TreeBASE (https:// treebase.org/treebase-web/home.html).

\section{Authors' contributions}

NEE proposed the research concept, designed the experiments, providing necessary tools for experiments, experimental instructions, conducted most of the experiments, analyzed and interpreted the data and wrote the manuscript. NME and SME carried out the experiments. All authors read and approved the final manuscript.

\section{Competing interests}

The authors declare that they have no competing interests.

\section{Consent for publication}

Not applicable.

Ethics approval and consent to participate Not applicable. 


\section{Received: 1 April 2016 Accepted: 6 September 2016}

\section{Published online: 20 September 2016}

\section{References}

1. MacLachlan J, Wotherspoon ATL, Ansell RO, Brooks CJW. Cholestero oxidase: sources, physical properties and analytical applications. J Steroid Biochem Mol Biol. 2000;72:169-95.

2. Ernst ND, Cleeman Jl. National cholesterol education program keeps a priority on lifestyle modification to decrease cardiovascular disease risk. Curr Opin Lipidol. 2002;13:69-73.

3. Paniangvait $P$, King $A J$, Jones $A D$, German $B G$. Cholesterol oxides in foods of animal origin. J Food Sci. 1995;60:1159-74.

4. Watanabe K, Shimizu H, Aihara H, Nakamura R, Suzuki Kl, Momagata K. Isolation and identification of cholesterol degradation Rhodococcus strains food of animal origin and their cholesterol oxidase activities. J Gen Appl Microbiol. 1986;32:137-47.

5. Doukyu N. Characteristics and biotechnological applications of microbial cholesterol oxidases. Appl Microbiol Biotechnol. 2009;83:825-37.

6. Cho HJ, Choi KP, Yamashita M, Morikawa H, Murooka Y. Introduction and expression of the Streptomyces cholesterol oxidase gene (choA), a potent insecticidal protein active against boil weevil larvae, into tobacco cells. Appl Microbiol Biotechnol. 1995;44:133-8.

7. Kumari L, Kanwar SS. Cholesterol oxidase and its applications. Adv Microbiol. 2012;2:49-65.

8. Arya SK, Datta M, Singh SP, Malhotra BD. Biosensor for total cholesterol estimation using $\mathrm{N}$-(2-aminoethyl)-3-aminopropyltrimethoxysilane self-assembled monolayer. Anal Bioanal Chem. 2007;389:2235-42.

9. Cheetham PS, Dunnill P, Lilly MD. The characterization and interconversion of three forms of cholesterol oxidase extracted from Nocardia rhodochrous. Biochem J. 1982;201:515-21.

10. Yazdi MT, Zahraei M, Aghaepour K, Kamranpour N. Purification and partial characterization of a cholesterol oxidase from Streptomyces fradiae. Enzyme Microb Technol. 2001:8:410-4.

11. Inouye Y, Tagnchi K, Fujii A, Ishimaru K, Nakamura S, Nomi R. Purification and characterization of extracellular $3 \beta$ - hydroxysteroid oxidase produced by Streptoverticillium cholesterolieum. Chem Pharm Bull. 1982:30:951-8.

12. Arima K, Nagasawa M, Bae M, Tamura G. Microbial transformation of sterols. Part I. Decomposition of cholesterol by microorganisms. Agric Biol Chem. 1969;33:1636-43

13. Brzostek A, Dziadek B, Rumijowska-Galewicz A, Pawelczyk J, Dziadek J. Cholesterol oxidase is required for virulence of Mycobacterium tuberculosis. FEMS Microbiol Lett. 2007;275:106-12.

14. Lashkarian H, Raheb Jamshid, Shahzamani Kiana, Shahbani Hossein, Shamsara Mehdi. Extracellular cholesterol oxidase from Rhodococcus sp.: Isolation and molecular characterization. Iran Biomed J. 2010;14(1 \& 2):49-57.

15. Yazdi MT, Kamranpour N, Zahraei M, Agaiepour K. Streptomyces fradiae, a potent producer of cholesterol oxidase. Iran J Sci Technol. 1999;10(3):151-7.

16. Kawato M, Shinobu R. A simple technique for the microscopical observation, memoirs of the Osaka University Liberal Arts and Education. Nat Sci. 1959;8:114-4

17. Shirling EB, Gottlieb D. Methods for characterization of Streptomyces species. Int J Syst Microbiol. 1966;16:313-40

18. Tresner H, Jean D, Hayes A, Backus EJ. Differential tolerance of streptomycetes to sodium chloride as a taxonomic aid. Appl Microbiol. 1968;16(8):1134-6.

19. Gordon RE, Barnett DA, Handerhan JE, Pang CH. Nocardia coeliaca, Nocardia autotrophica, and the Nocardia strain. Int J Syst Bacteriol. 1974;24:54-63.

20. Williams ST, Goodfellow M, Alderson G, Wllington EM, Sneath PH, Sacki MJ. Numerical classification of Streptomyces and related genera. J Gen Microbiol. 1983;129:1747-813.

21. Waksman SA. The actinomycetes. Classification, identification and description of genera and species. Baltimore: Williams and Wilkins Company; 1961. p. 327

22. Cowan ST, Steel KL. Cowan and Steel's manual for the identification of medical bacteria. 2nd ed. Cambridge: Cambridge University Press; 1974.

23. Nitsch B, Kutzner HJ. Egg - yolk as a diagnostic medium for streptomycetes. Experientia. 1969;25:113-6.

24. Ariffin H, Abdullah N, Umi Kalsom MS, Shirai Y, Hassan MA. Production and characterization of cellulase by Bacillus pumilus EB3. Int J Eng Technol. 2006:3:47-53.
25. Mishra S, Behera N. Amylase activity of a starch degrading bacteria isolated from soil receiving kitchen wastes. Afr J Biotechnol. 2008;7(18):3326-31.

26. Sambrook J, Fritsch EF, Maniaties T. Molecular cloning: A laboratory Manual 2nd Cold. New York: Spring. Harbor Laboratory press, Cold Spring Harbor; 1989.

27. El-Naggar NE, Sherief AA, Hamza SS. Streptomyces aegyptia sp. nov., a novel cellulolytic streptomycete isolated from soil in Egypt. Afr J Microbiol Res. 2001;5:5308-15.

28. Altschul SF, Madden TL, Schaffer AA. Gapped blast and psi-blast: a new generation of protein database search programs. Nucleic Acids Res. 1997; 25(17):3389-402

29. Tamura K, Dudley J, Nei M, Kumar S. MEGA4: Molecular evolutionary genetics analysis (MEGA) software version 4.0. Mol Biol Evo. 2007:24(8):1596-9.

30. Saitou N, Nei M. The neighbor-joining method: a new method for reconstructing phylogenetic trees. Mol Biol Evo. 1987:4:406-25.

31. Krishnan S, Prapulla SG, Rajalakshmi D, Misra MC, Karanth NG. Screening and selection of media components for lactic acid production using Plackett-Burman design. Bioprocess Engineering. 1998;19(1):61-5.

32. El-Naggar NE, El-Bindary AA, Nour NS. Production of antimicrobial agent inhibitory to some human pathogenic multidrug-resistant bacteria and Candida albicans by Streptomyces sp. NEAE-1. Int J Pharmacol. 2013;9(6): 335-47.

33. Plackett RL, Burnam JP. The design of optimum multifactorial experiments. Biometrika. 1946;33:305-25

34. Williams ST, Goodfellow M, Alderson G. Genus Streptomyces.Waksman and Henrici 1943, 339AL. In: Williams ST, Sharpe ME, Holt JG, editors. Bergey's manual of systematic bacteriology. Baltimore: Williams and Wilkins; 1989. p. 2452-92.

35. Goodfellow M, Kampfer P, Busse HJ. Bergey's Manual of Systematic Bacteriology, vol. 5 of The Actinobacteria Part A. 2nd ed. NewYork: Springer; 2012.

36. Kaushik R, Saran S, Isar J, Saxena RK. Statistical optimization of medium components and growth conditions by response surface methodology to enhance lipase production by Aspergillus carneus. J Mol Catal B-Enzym. 2006; 40(3-4):121-6.

37. Akhnazarova S, Kafarov V. Experiment optimization in chemistry and chemical engineering. Moscow, Russia: Mir Publishers; 1982

38. Varma R, Nene S. Biosynthesis of cholesterol oxidase by Streptomyces lavendulae NCIM 2421. Enzyme Microb Tech. 2003:33:286-91.

39. Nagasawa M, Bae M, Tamura G, Arima K. Microbial transformation of steroids. Part II. Cleavage of sterols side chains by microorganisms. Agric Biol Chem. 1969;33:1644-50.

40. Yehia HM, Hassanein WA, Ibraheim SM. Purification and characterisation of the extracellular cholesterol oxidase enzyme from Enterococcus hirae. BMC Microbiol. 2015;15:178. http://doi.org/10.1186/s12866-015-0517-2.

41. Sojo MM, Bru RR, Garcia FF. Rhodococcus erythropolis ATCC 25544 as a suitable source of cholesterol oxidase: cell-linked and extracellular enzyme synthesis, purification and concentration. BMC Microbiol. 2002;2:3. doi:10. 1186/1472-6750-2-3

42. Jain P, Pundir RK. Effect of fermentation medium, $\mathrm{pH}$ and temperature variations on antibacterial soil fungal metabolite production. J Agr Sci Tech. 2011;7(2):247-69.

43. Solingen VP, Meijer D, Kleij WA, Branett C, Bolle R, Power SD, Jones BE. Cloning and expression of an endocellulase gene from a novel Streptomyces isolated from an east African soda lake. Extremophiles. 2001:5:333-4

44. Voelker F, Altaba S. Nitrogen source governs the patterns of growth and pristinamycin production in Streptomyces pristinaespiralis. Microbiol. 2001;147(9):2447-59.

45. Chauhan AK, Survase SA, Kishenkumar J, Annapure US. Medium optimization by orthogonal array and response surface methodology for cholesterol oxidase production by Streptomyces lavendulae NCIM 2499. J Gen Appl Microbiol. 2009:55:171-80.

46. Sabry AA. Decomposition of cholesterol by some organisms isolated from certain Egyption soils, M.Sc. Thesis. Bot. and Microbiol. Cairo: Dept. Al-Azhar University; 1994

47. Liu WH, Meng MH, Chen KS. Purification and some properties of cholestero oxidases produced by an inducible and a constitutive mutant of Arthrobacter simplex. Agric Biol Chem. 1988:52(2):413-8.

48. Ahmad S. Studies on production characterization and application potential of cholesterol oxidase from Rhodococcus sp. NCIM 2891; A Thesis. Assam: Indian Institute of Technology Guwahati; 2014 
49. Moradpour Z, Ghasemian A, Safari A, Mohkam M, Ghasemi Y. Isolation, molecular identification and statistical optimization of culture condition for a new extracellular cholesterol oxidase-producing strain using response surface methodology. Ann Microbiol. 2012. doi:10.1007/s13213-012-0547-z.

50. Lee MT, Chen WC, Chou CC. Medium improvement by orthogonal array designs for cholesterol oxidase production by Rhodococcus equi No. 23. Process Biochem. 1997;32(8):697-703.

51. Weisberg S. Applied linear regression. 2nd ed. New York: John Wiley \& Sons Inc.; 1985.

52. Chen XC, Bai JX, Cao JM, Li ZJ, Xiong J, Zhang L, Hong Y, Ying HJ. Medium optimization for the production of cyclic adenosine 3', 5'-monophosphate by Microbacterium sp. no. 205 using response surface methodology. Biores Technol. 2009;100:919-24

53. Box GEP, Hunter WG, Hunter JS. Statistics for Experimenters. New York: John Wiley \& Sons; 1978.

Submit your next manuscript to BioMed Central and we will help you at every step:

- We accept pre-submission inquiries

- Our selector tool helps you to find the most relevant journal

- We provide round the clock customer support

- Convenient online submission

- Thorough peer review

- Inclusion in PubMed and all major indexing services

- Maximum visibility for your research

Submit your manuscript at www.biomedcentral.com/submit 